\title{
Efficient Identification of Corn Cultivation Area with Multitemporal Synthetic Aperture Radar and Optical Images in the Google Earth Engine Cloud Platform
}

\author{
Fuyou Tian ${ }^{1,2}$, Bingfang $\mathrm{Wu}^{1,2, *}$, Hongwei Zeng ${ }^{1}$, Xin Zhang ${ }^{1(1)}$ and Jiaming $\mathrm{Xu}^{1,2}{ }^{1 /()}$ \\ 1 State Key Laboratory of Remote Sensing Science, Institute of Remote Sensing and Digital Earth, \\ Chinese Academy of Sciences, Olympic Village Science Park, W. Beichen Road, Beijing 100101, China; \\ tianfy@radi.ac.cn (F.T.); zenghw@radi.ac.cn (H.Z.); zhangxin1010@radi.ac.cn (X.Z.); xujm@radi.ac.cn (J.X.) \\ 2 University of Chinese Academy of Sciences, Beijing 100049, China \\ * Correspondence: wubf@radi.ac.cn
}

Received: 15 January 2019; Accepted: 11 March 2019; Published: 14 March 2019

\begin{abstract}
The distribution of corn cultivation areas is crucial for ensuring food security, eradicating hunger, adjusting crop structures, and managing water resources. The emergence of high-resolution images, such as Sentinel-1 and Sentinel-2, enables the identification of corn at the field scale, and these images can be applied on a large scale with the support of cloud computing technology. Hebei Province is the major production area of corn in China, and faces serious groundwater overexploitation due to irrigation. Corn was mapped using multitemporal synthetic aperture radar (SAR) and optical images in the Google Earth Engine (GEE) cloud platform. A total of 1712 scenes of Sentinel-2 data and 206 scenes of Sentinel-1 data acquired from June to October 2017 were processed to composite image metrics as input to a random forest (RF) classifier. To avoid speckle noise in the classification results, the pixel-based classification result was integrated with the object segmentation boundary completed in eCognition software to generate an object-based corn map according to crop intensity. The results indicated that the approach using multitemporal SAR and optical images in the GEE cloud platform is reliable for corn mapping. The corn map had a high F1-Score of $90.08 \%$ and overall accuracy of $89.89 \%$ according to the test dataset, which was not involved in model training. The corn area estimated from optical and SAR images was well correlated with the census data, with an $\mathrm{R}^{2}=0.91$ and a root mean square error (RMSE) of $470.90 \mathrm{~km}^{2}$. The results of the corn map are expected to provide detailed information for optimizing crop structure and water management, which are critical issues in this region.
\end{abstract}

Keywords: corn mapping; optical and SAR images; object-based; Sentinel-1 and 2; Google Earth Engine

\section{Introduction}

Food security a major challenge to the sustainable development of human beings [1,2], and the eradication of hunger is the second target of the United Nation (UN)'s Sustainable Development Goals (SDGs) [3]. Corn serves as livestock feed, industrial raw material, and human food, and is one of the cardinal crops in the world. Corn cultivated areas account for $13 \%$ of the total croplands on Earth and rank second among the major crop categories [2]. In the Hai basin, serious overexploitation of groundwater is occurring [4]; irrigation accounts for $70-80 \%$ of the total water use, and is the chief reason for groundwater depletion [5]. Identifying corn-cropped areas accurately and efficiently is essential for ensuring food security, providing fundamental information to estimate crop yields, make decisions, and adjust crop structures [6], and managing water resources, because corn is a crucial C4 crop with the highest water-use efficiency, which is important for global primary production [7]. 
Traditional approaches to obtaining crop information, such as ground surveys and sampling, are time consuming, labor intensive, and costly, and cannot obtain continuous spatial distribution data for crops [1,6]. Earth observation satellites that monitor and regularly revisit cropland are inexpensive and excellent data sources that provide full spatial detailed information for crop mapping [8,9]. In recent decades, many studies have focused on crop monitoring with optical [10-14] and synthetic aperture radar (SAR) images [1,15-18]. Multitemporal and time series data are powerful tools for identifying different crops and handling the problem of spectral similarity in heterogeneous underlying surfaces in single-period imagery [19-23]. The use of coarse spatial resolution images as original data at scales of hundreds of meters, such as Moderate Resolution Imaging Spectroradiometer (MODIS) and Advanced Very High-Resolution Radiometer (AVHRR), is predominant in previous studies because of the fine temporal resolution of the Aqua and Terra satellites. These two satellites revisit the same location at least four times per day, and provide the composition products for free [24-28]. To distinguish cropland and grassland, Estel et al. used MODIS normalized differenced vegetation index (NDVI) time series and random forest (RF) classifiers and achieved an overall accuracy of 90.1\% [20]. Using growing degree days information and a Gaussian mixture model, Skakun et al. mapped large areas of winter crops with MODIS NDVI data and obtained good consistency with the official statistical data [25]. However, the spatial resolutions of MODIS and AVHRR were so coarse that each pixel could contain mixtures of different crops or vegetation and crops, especially in China [21]. Since 2008, 30-m resolution Landsat imagery has been freely available, and it has also been widely used in crop classification tasks [29-33]. Dong et al. mapped the extent of the paddy rice crop in northeastern Asia based on Landsat 8 images, and achieved excellent results with a user accuracy of 92\% [10]. Song et al. recognized a soybean cultivated area in United States with medium-resolution satellite Landsat data and obtained an overall accuracy of 84\% [8]. However, the revisiting period of Landsat was half a month, and few images were available during the crop-growing season $[9,21]$.

Although contradictions are observed between the spatial and temporal resolution for satellite remote sensing data, these contradictions have been partially alleviated since the Sentinel-2 constellation was launched in June 2015 and March 2017, which shortened the revisiting cycle to 10 days for single satellites and five days for satellite constellations. To mine agricultural information from Sentinel-2 data, the European Space Agency launched the 'Sentinel-2 for Agriculture' project in 2014 for cropland and crop-type mapping [34-37]. Due to the revisiting frequency and high resolution, Sentinel-2 data represent an important data source for crop mapping [13]. The volume of available SAR data has increased with the Sentinel-1A and B launches in April 2014 and April 2016, respectively. In contrast with optical satellite images, SAR signals can pass through clouds and obtain temporally continuous data regardless of the weather conditions [38]. Considering the imaging mechanism of SAR, backscatter is sensitive to the dielectric of the object and structure, including the size, shape, and orientation distribution of the scatterers [39,40]. The feasibility of using crop classification with SAR data has been proven in many studies [41-44].

With the emergence of cloud-based calculations, the computing capability has been greatly improved in recent years. Google, Amazon, Microsoft, and Alibaba have introduced cloud computing products, and Google and Amazon have archived a large catalogue of satellite imagery and provided geo-cloud computing for Earth science applications at the global scale in Google Earth Engine (GEE) and Amazon Web Service (AWS), respectively [10,45]. GEE is an online programmable platform that includes preprocessed satellite data collection and assembles a conventional machine learning method and provides a visual user interface. The cloud-based platform has also been widely used for mapping forests [46], settlements and populations [47], African croplands [48], Indian urban boundaries [49], and land cover $[50,51]$. Dong et al. identified paddy rice cultivated areas in northeastern Asia in GEE using approximately 3290 Landsat 7 and 8 scenes with millions of servers around the world within one day, and attested to the power of this parallel processing, super-computing platform in crop-type mapping [10]. Our question is whether emerging cloud computing can be used to efficiently map corn on a large scale. 
The objective of this research is to develop a cloud computing-based method using optical and SAR images to identify the extent of corn cultivation at a 10-m resolution on the North China Plain. First, metric composites were calculated based on optical and SAR data collections, including Sentinel-2 and Sentinel-1 images. Then, these metrics were used as input for a random forest classifier in GEE to generate a pixel-based corn distribution. Finally, the pixel-based classification result was integrated with the object-based segmentation result. Specifically, the results of this research answer the following three questions: (1) Is the cloud computing-based method using optical and SAR images reliable and practical for mapping corn in a large area? (2) How well can the Sentinel-1 SAR data improve corn mapping? (3) Can GEE effectively support global scale crop thematic maps in the future?

\section{Materials}

\subsection{Study Area}

The study area is Hebei Province, which includes 11 prefecture-level cities (Figure 1). Hebei is adjacent to the Bohai Sea to the east, Beijing and Tianjin in the inner area, Taihang Mountain to the west, and Yanshan to the north, and it encompasses the North China Plain to the southeast, which is Hebei Province's major corn production area. The total cropland area of Hebei Province is 65,200 km² (out of $188,800 \mathrm{~km}^{2}$ of total province area), and the corn area is $31,910 \mathrm{~km}^{2}$, accounting for approximately $48.94 \%$ of the total cropland according to 2016 national census data [52].

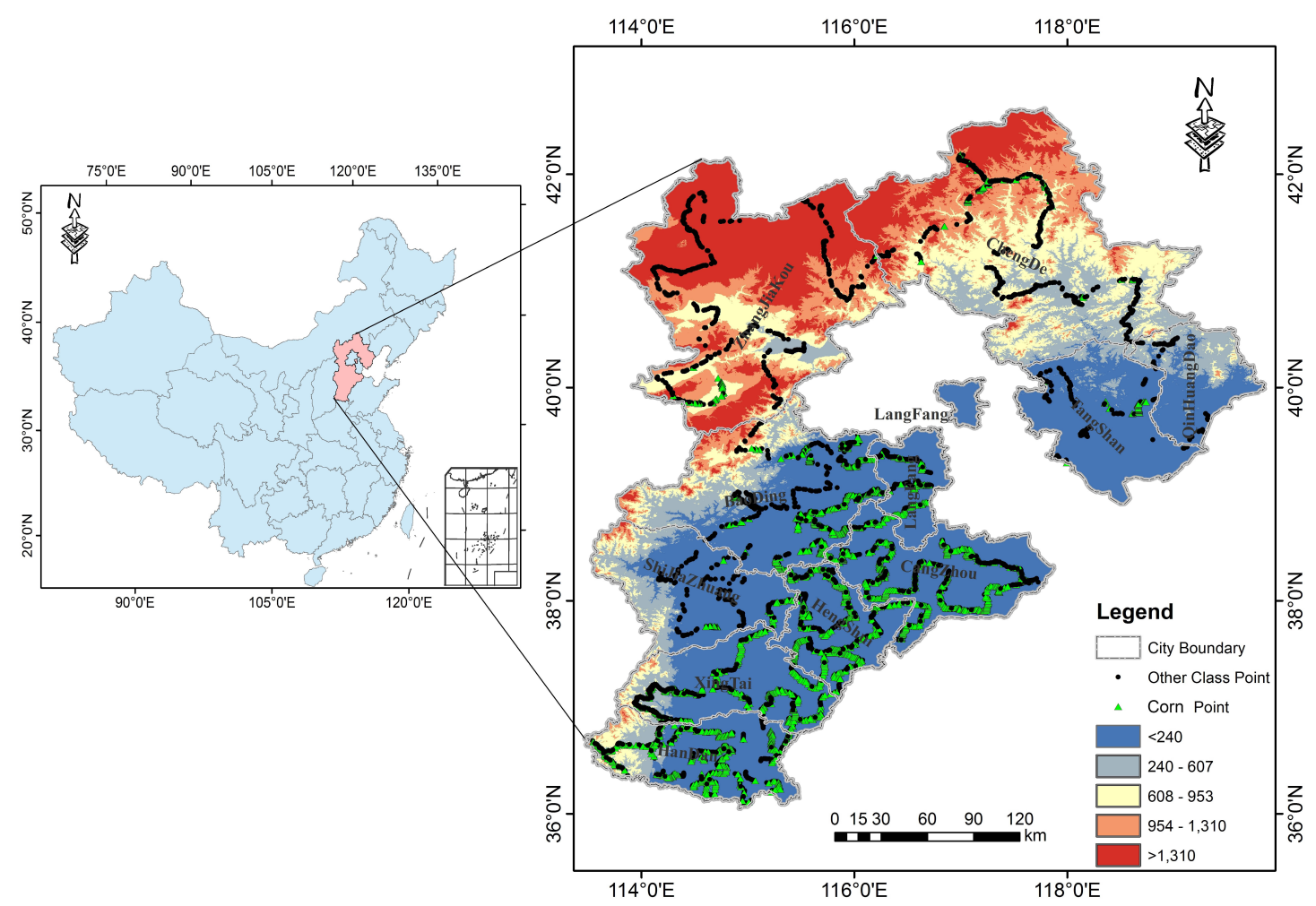

Figure 1. Hebei Province, including 11 prefecture-level cities, is the area of interest in this study. The topographical characteristics of Hebei Province and the field sample point location are shown in the map on the right. Corn points are labeled as green triangle symbols, while other class points are shown as black circles.

This region has a temperate continental monsoon climate with dry, cold winters and hot, humid summers. The annual average precipitation is $\sim 484 \mathrm{~mm}$, and the frost-free period lasts between 81-204 days from north to south in this region, ensuring one to two growing seasons. The crops in Hebei, except in the northwest region, are grown for two seasons: winter wheat crops are grown during the prior year's winter (October to November) and harvested in the summer (May to June) of 
the following year, and the second season is corn or soybean crops grown in the summer (May to June) and harvested in autumn (September to October) of the same year. Occasionally, cotton is sown in the spring (March to April) and harvested in the autumn (September to October). In the northwestern part of this region, including Chengde, Zhangjiakou and certain mountainous areas, corn is planted in the spring (April to May) and harvested in the autumn (September to October). Details and further information about the major crop calendar in this region are exhibited in Figure 2.

\begin{tabular}{|c|c|c|c|c|c|c|c|c|c|c|c|c|}
\hline & Jan & Feb & Mar & Apr & May & Jun & Jul & Aug & Sep & Oct & Nov & Dec \\
\hline Wheat (Winter) & 当 & 㫧 & 茟 & 当 & 当 & 当 & & & & 首 & 当 & 断 \\
\hline Corn (Summer) & & & & & $\checkmark$ & $\theta$ & 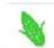 & 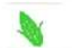 & 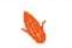 & $\theta$ & & \\
\hline Soybean & & & & & ø̆ & ஜั & ஜூ & ซั & Øॅ & ฮั & & \\
\hline Corn (Spring) & & & & 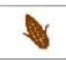 & 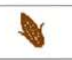 & 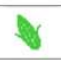 & v & $\gamma$ & $v$ & $\gamma$ & & \\
\hline Cotton & & & 4 & 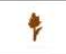 & $\phi$ & $\phi$ & $\$$ & $\phi$ & 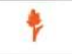 & 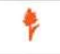 & & \\
\hline
\end{tabular}

Figure 2. Crop calendar for the dominant crops in Hebei Province.

\subsection{Sentinel-2 Imagery and Preprocessing}

A total of 1712 scenes of Sentinel-2 orthorectified images (Level-1C) acquired between 1 June and 31 October 2017, in 44 footprints were imported as optical imagery data sources in this research, and were included in the GEE platform as an image collection of the Sentinel-2 Multi-Spectral Instrument (MSI) Level-1C dataset. The total number of observations for each pixel was counted in the GEE platform, and is shown in Figure 3a. Sentinel-2 revisits each pixel 40.62 times on average and 12 times at minimum. Sentinel-2 had 20-30 observations in $44.1 \%$ of the total area and 50-60 observations in 34.4\% of the entire study area. The frequent revisits in the bright green area (Figure 3a) were due to repeated observations, which can provide abundant information for metric composites and corn identification.

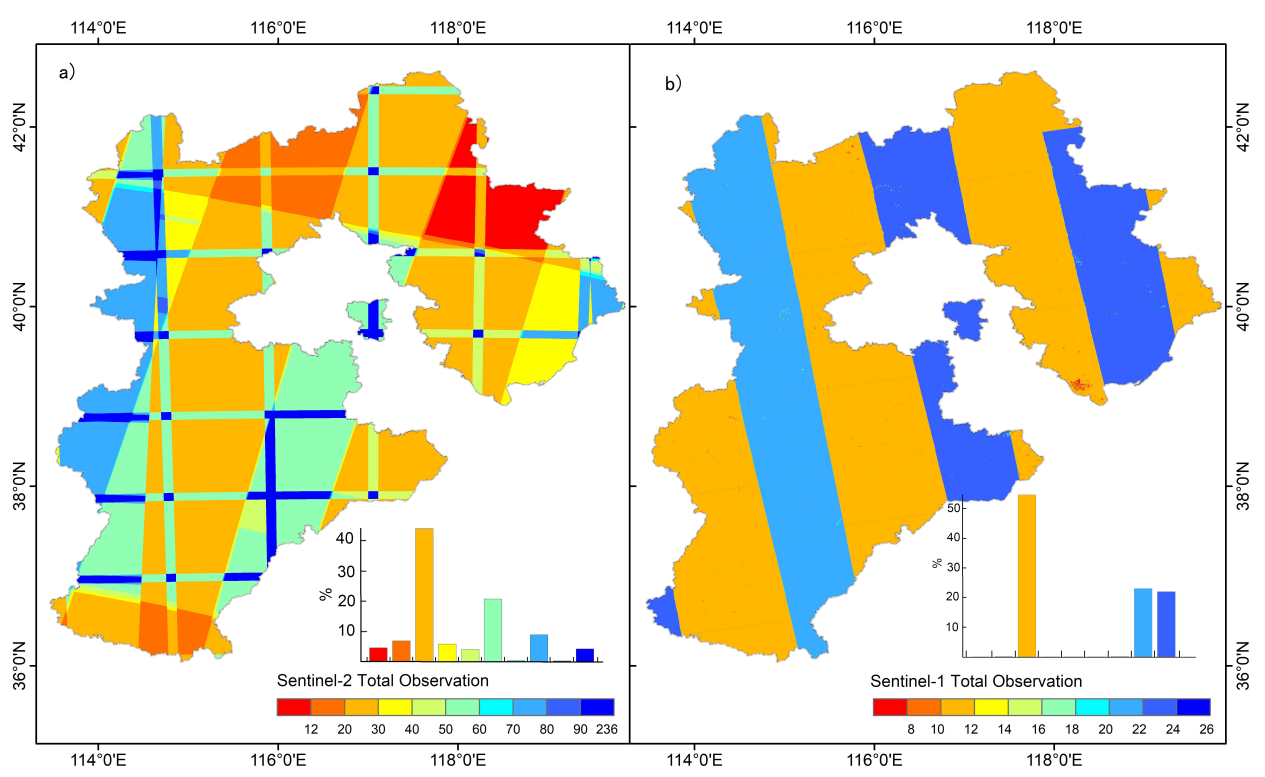

Figure 3. Total observation numbers of (a) Sentinel-2 and (b) Sentinel-1 images acquired between 1 June and 31 October 2017, in Hebei Province. The embedded histograms depict the distribution of the number of Sentinel images with different color bars, and the color is same as the map legends.

The Sentinel-2 collection contains 13 MSI bands of top of atmosphere (TOA) reflectance scaled by 10,000 . Invalid observations were removed according to the quality assessment band (QA60) that 
labeled opaque and cirrus clouds in the bitmask. Both of these cloud types were excluded to eliminate the effects of clouds. Six spectral bands, including blue, green, red, NIR (near infrared), SWIR1 (shortwave infrared), and SWIR2, were selected and investigated to participate in the classification task. The former four bands with 10-m spatial resolutions were normal bands that were used to distinguish vegetation, while the latter two bands with 20-m spatial resolution were tested in relation to crop water content and have the potential to recognize corn and soybean crops [53]. In addition, three familiar and useful vegetation indices were employed, including the NDVI [54], enhanced vegetation index (EVI) [55], and land surface water index (LSWI) [56], which is defined with the following formulas:

$$
\begin{gathered}
\mathrm{EVI}=2.5 \times \frac{N I R-R E D}{N I R+6 \times R E D-7.5 \times B L U E+1} \\
\mathrm{LSWI}=\frac{N I R-S W I R 1}{N I R+S W I R 2} \\
\mathrm{NDVI}=\frac{N I R-R E D}{N I R+R E D}
\end{gathered}
$$

The NDVI is commonly used to determine the photosynthetic capacity of plants because healthy vegetation absorbs more red light than NIR light [57]. The EVI has been shown to be less sensitive to atmospheric conditions involving blue bands, and can reduce the effects of saturated NDVI data because of high leaf area biomass [55]. Introduced by Xiao, the LSWI is an indicator that is designed to estimate canopy water thickness by including the SWIR band, which is sensitive to crop and soil water content [56].

\subsection{Sentinel-1 SAR Data}

Altogether, 206 scenes of Sentinel-1 dual-polarization C-band SAR instrument imagery, which have VV (Single co-polarization, vertical transmit/vertical receive) and VH (Dual-band cross-polarization, vertical transmit/horizontal receive) bands, were employed in the crop extent identification, and they have been archived in GEE as the Sentinel-1 SAR Ground Range Detected (GRD) collection. All of the images were preprocessed by the Sentinel-1 Toolbox, and preprocessing included thermal noise removal, radiometer calibration orthorectification with a Shuttle Radar Topography Mission (SRTM) or Advanced Spaceborne Thermal Emission and Reflection Radiometer (ASTER) DEM (Digital Elevation Model), and conversion to a backscatter coefficient $\left(\sigma^{0}\right)$ in decibels (dB) [58].

Figure $3 \mathrm{~b}$ shows the Sentinel-1 ascending observation number between 1 June and 31 October 2017 for each pixel. Sentinel-1 had an average of 16.5 observations and a maximum of 26 observations. The SAR imagery covered $54.7 \%$ of the total pixels 10 to 12 times, $23.0 \%$ of the entire area 20 to 22 times, and $21 \%$ of the entire area 20 to 24 times. Compared with optical images for which repeat observations can provide more information for a time series, the overlap of SAR is redundant, because the incidence in overlap area ranges from approximately 30 to 50 degrees. Therefore, the image with a lower incidence angle is kept in the repeated observational areas [1].

\subsection{Reference Dataset}

A total of 8279 points, including corn (1811 points), other crops (1770 points), urban (1672 points), water (1463 points), and forest (1563 points) points were collected in the field using GVG, which is geographic information smartphone software [59]. GVG is an integrated system based on GPS for figuring position, video for capturing photo information, and GIS for managing locational information. The app is capable of collecting thousands of photos with geotags efficiently, and can be used to mark the attribute of the crop type. The app can be downloaded freely in the Google app store [59]. All of the points are shown in Figure 1. The field points were collected using the stratified sampling method. The first level is all of the study area, which is dominated by a winter wheat-corn-soybean rotation. The second level is the prefecture-level city. We sampled many field points in all 11 prefecture-level 
cities, as shown in Figure 1. Several counties with representative crop types in each prefecture-level city were selected to collect fields points along county and rural roads, which is the third level. To avoid the problem of sample imbalance, stratified random sampling was applied to separate the training and testing datasets based on class. For each class, 900 points were randomly selected for training, and the rest of the field points were used to assess the accuracy. The SRTM DEM archived in the GEE with a spatial resolution of $30 \mathrm{~m}$ was used to obtain elevation and slope, because the topographic information was helpful in land cover recognition [60].

\section{Methodology}

The methodology flow chart used in this research is exhibited in Figure 4. Combined with Sentinel C-band monthly composites and percentile composites, interval mean composites and percentile composites of Sentinel-2 were used to identify corn. Moreover, elevation and slope are auxiliary data in the classification. A RF classifier incorporated in the GEE platform was employed to recognize water, urban, forest, corn, and other crops. We integrated pixel-based classification results and object-based segmentation generated by eCognition software and Sentinel-2 cloud-free composites to remove the 'salt-and-pepper effect' [61]. Finally, certain field points that were not used to train the model and census data were used to jointly inspect the accuracy.

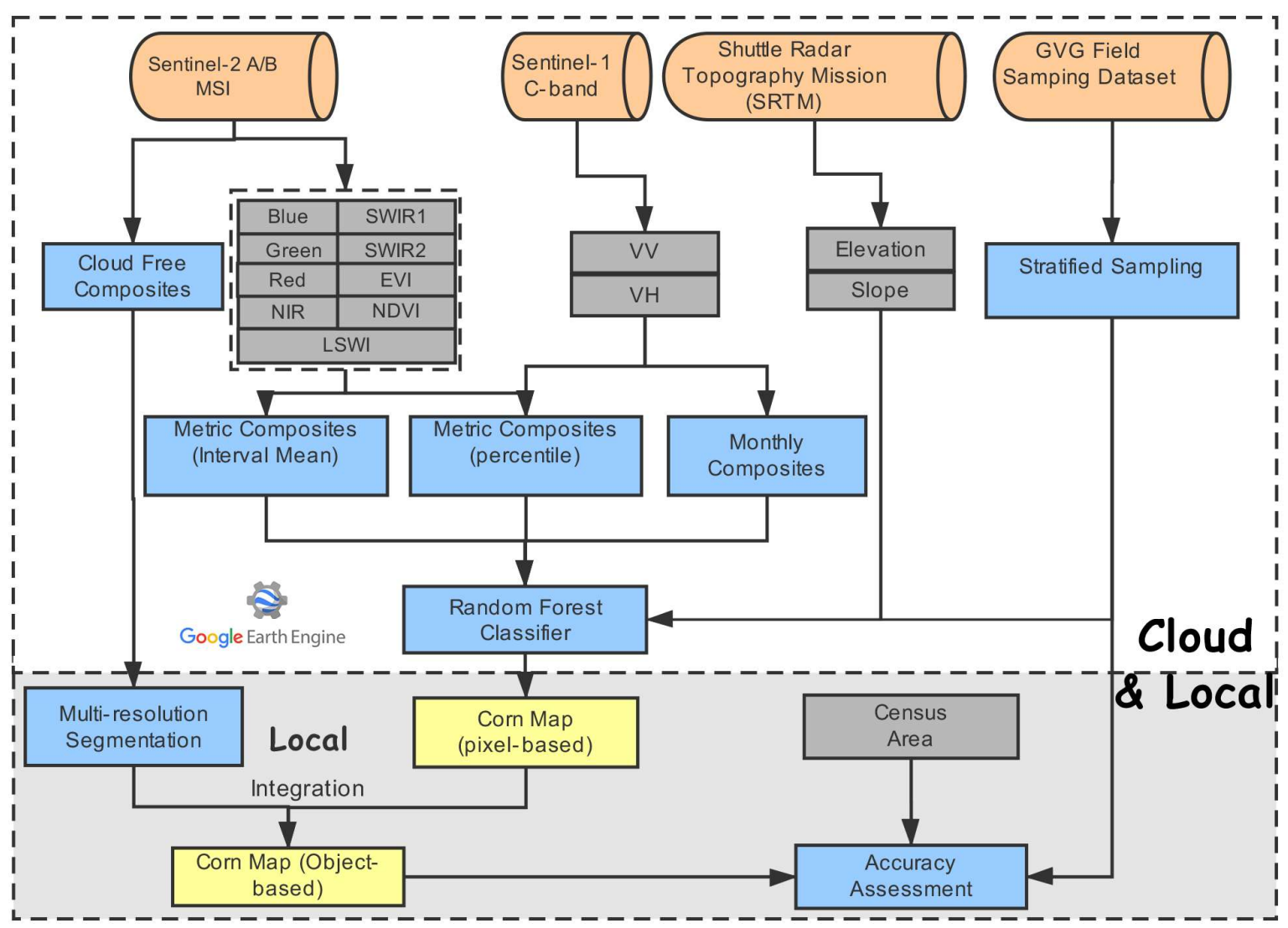

Figure 4. Workflow for cloud computing-based methods using optical and synthetic aperture radar (SAR) images. The pixel-based classification of corn using random forests (RFs) with composite metrics and the integration between pixel-based results and multiresolution object-based segmentation were the two major modules.

\subsection{Image Compositing}

A monthly and metric composite of multitemporal images was adopted for the time series analysis. To take advantage of the time series of images and avoid the problem that the number of available values was uncertain due to cloudiness during the rainy month and uneven revisit times, statistical 
analysis of the series was employed to distinguish different crops. The percentile and mean value of the series are commonly used statistical measures, and have been applied successfully to identify tree cover [46,62] and paddy rice [1]. The percentile and mean value can be calculated regardless of the length of the series or the lack of complete data. Therefore, we choose the percentile and interval mean value as representative features of the series. For Sentinel-2, two groups of metrics were calculated for six reflectance and three VI bands [46,50,62]: (1) Percentile composites: 10\%, 25\%, 50\%, 75\%, and 95\% percentiles were produced in the GEE platform. First, all of the preprocessed Sentinel-2 data from June to October were stored in 'ImageCollection', which is a stack or time series of images and in which the images are easily filtered by a date range and footprint. Then, the collection of images was converted to a two-dimensional array by leveraging the method of 'ImageCollection.toArray()' in GEE. The two-dimensional array stored the entire observations along the temporal and band dimension for each pixel, which is flexible enough to handle the time series images. Then, a percentile reducer was applied to extract the percentiles along the temporal dimension in the two-dimensional array. (2) The mean values of the $10-25 \%, 10-90 \%, 10-100 \%, 25-50 \%, 25-75 \%, 50-75 \%, 75-90 \%, 90-100 \%$, and $0-100 \%$ intervals were calculated for six spectral and three vegetation indices to determine the value between the two selected percentiles for each pixel across all of the images, which was conducted in GEE with the 'intervalMean()' reduction method. Considering two sample points of corn and another crop (cotton) as an example (Figure 5), the red line represents the NDVI time series of a rotation of winter wheat and summer corn, which is dominant in Hebei Province, while the green line shows the NDVI time series of cotton. The NDVI time series is exhibited in Figure 5a, while the series of quantiles sorted by value are shown in Figure $5 \mathrm{~b}$. We typically prefer to interpret the time series according to time, but the number of available values was uncertain due to cloudiness during the rainy month and uneven revisit times. The lack of some data did not affect the percentile composites as long as the inflection point was recorded. Additionally, the slight deviation of the crop calendar or curve shift did not change these two groups of metrics, which is useful for large-scale applications with similar but not identical crop calendars [1].

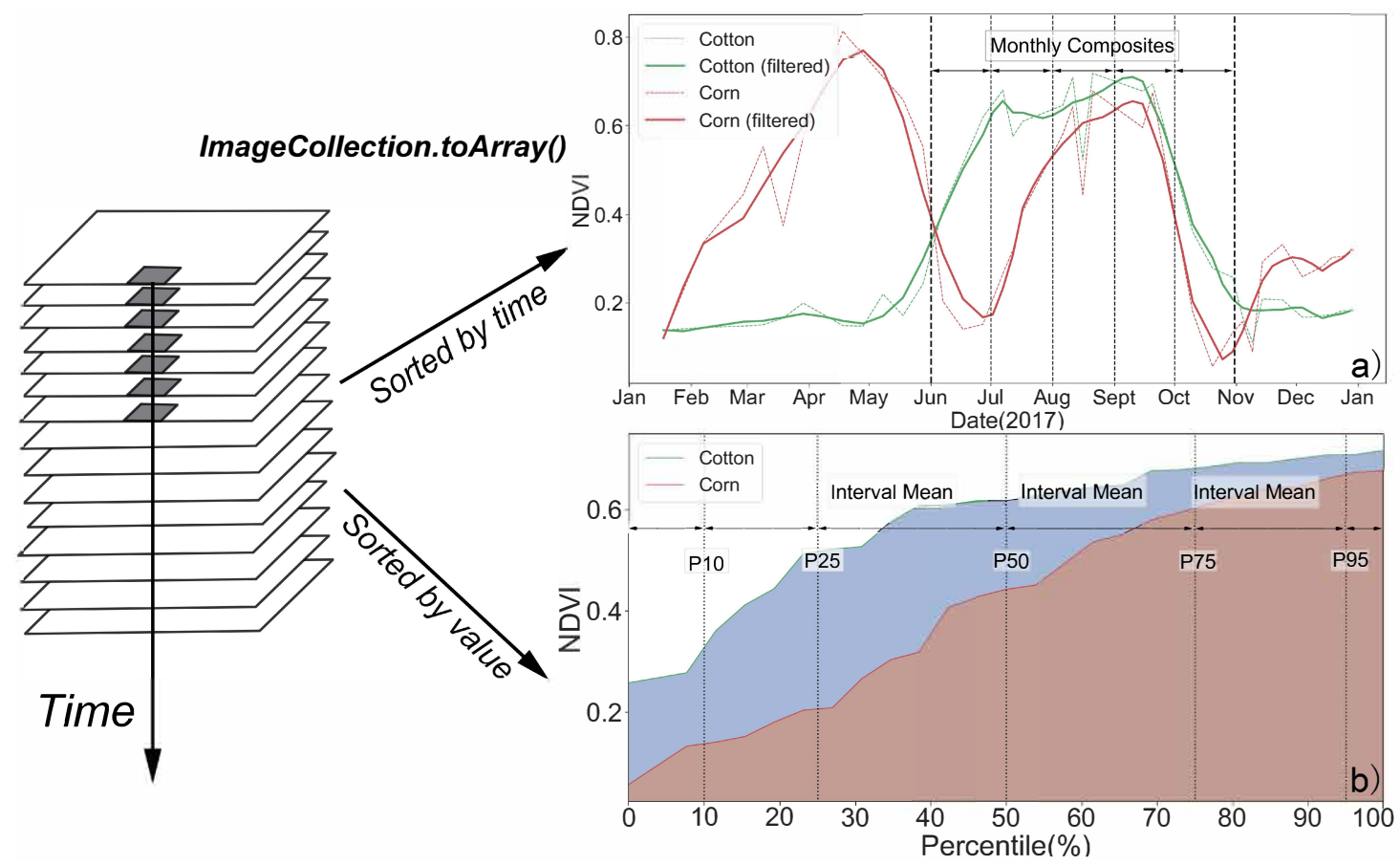

Figure 5. Example of monthly and metric composites for corn and other crops (cotton). In (a), the original NDVI time series of corn and other crops are shown as red and green dashed lines, respectively. The solid line is the smoothed time series with a Savitzky-Golay filter. The percentile and interval mean composites are shown in (b). 
For Sentinel-1, the number of available values was also uncertain not due to cloudiness, but rather due to the different revisit times. Two groups of metrics for the VV and VH bands were created to represent the series of images: (1) For the monthly composites, the median value of the June, July, August, September, and October data was measured to obtain the phenology information. The monthly composites are applicable for only SAR data due to the continuity of the data, regardless of cloudiness. We divided images into five groups (June through October) according to the month of acquisition. By converting the image collection to an array in the GEE platform, which is the process as used in Sentinel-2 described above, the median value of each monthly group was calculated for each pixel. (2) For the percentile composites, 10\%, 25\%, 50\%, 75\%, and 95\% percentiles were calculated for SAR images as for optical images. In total, 148 features, including 126 features from optical images, 20 from SAR images, and two features regarding topography, were input into the classification task.

\subsection{Pixel-Based Classification}

The RF classifier that uses an ensemble of trees [63] was employed in this research. It has been widely used in recent classification studies [1,2,13], and achieves a higher level of accuracy than the maximum likelihood and decision tree methods [64]. The random selection of features and samples was conducted in the RF classifier, thus solving the problem of overfitting and the 'curse of dimensionality', which is why this method was named 'random forest'. Compared with other machine learning methods, only approximately two-thirds of the training samples are used in the training model, so that the RF will not overfit the data. The remaining samples, known as 'out-of-bag' (OOB), will be used to validate the model, and the OOB accuracy is an overall unbiased estimation. The quantitative measurement of feature importance can be evaluated with OOB data when the permutation of features is tested in a random selection of features.

We conducted a RF classifier in the GEE platform, in which the number of decision trees and variables in each node were required. The classification accuracy was not as sensitive to the number of variables in each node [2]; thus, the parameters were set as the defaults. Although accuracy converges when the number of trees exceeds 200, 300 decision trees were set up in RF, because an increase in this parameter will not cause overtraining problems.

\subsection{Object Segmentation and Integration with Pixel-Based Results}

Based on the homogeneity of the spectral value, the image can be segmented into many small-scale objects consisting of several pixels to avoid the noise of pixel-based classification. In this paper, multiresolution segmentation in eCognition software was employed in the cloud-free composite segmentation. The segmentation scale, shape, and compactness were the three major parameters that first determined the size of the object, while the last two set the threshold of relative homogeneity, including the color and shape [65].

Determining the optimal scale is a critical step in performing multiresolution segmentation [66]. We adopted the estimation of scale parameter (ESP) tool to select the appropriate scale of segmentation. Introduced by Drăguţ, the ESP tool is commonly used to fit the scale parameter [67,68]. The ESP tool iteratively calculated the local variance (LV) of object heterogeneity, and the local maximum in the rate of change (ROC) curve for LV indicated the potential optimal scale for the scene. As shown in Figure 6, the ROC curve suggested that 52,64, 80, 88, and 96 were the optimal scales for segmentation. Considering that the cropland area per capita was only 0.126 ha in 2012 according to the National Bureau of Statistics [69], the smallest potential optimal scale of 52 was selected as the optimal scale to segment the fragmented and heterogeneous cropland. At this scale, the complex landscape can be depicted well (Figure 7c). Hence, we conducted multiresolution segmentation with a scale of 52 and selected 0.5 and 0.3 for compactness and shape, respectively. 


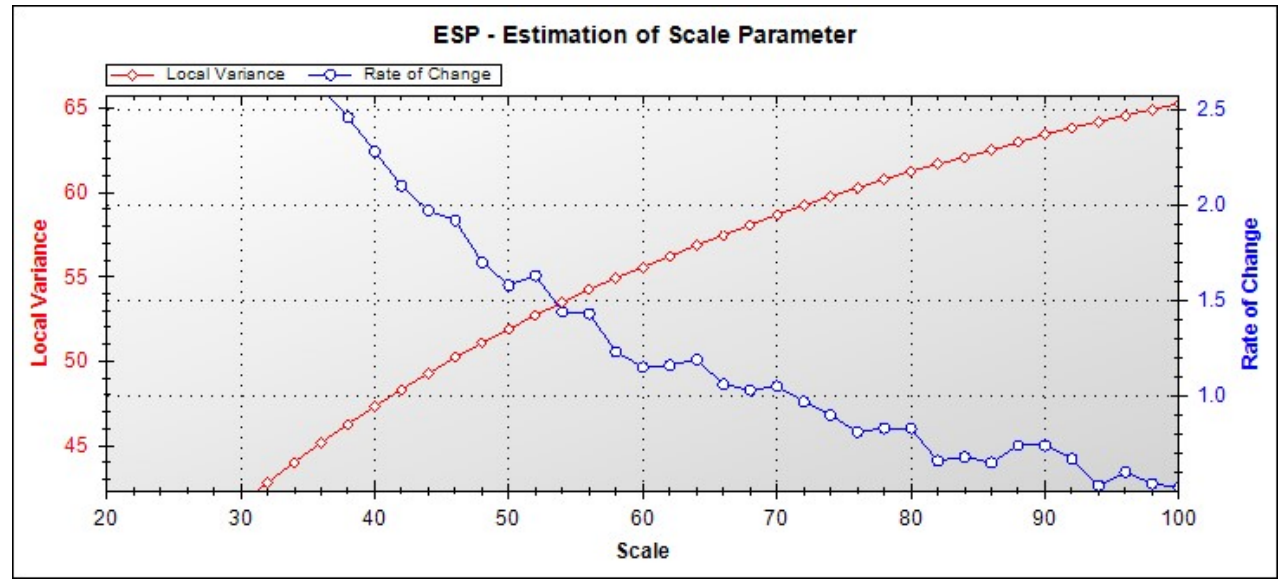

Figure 6. Curve of the local variable and rate of change graph exported from the estimation of scale parameter; the local maximum is the potential optimal scale for the scene, indicating that $52,64,80,88$, and 96 are potential scales for segmentation.
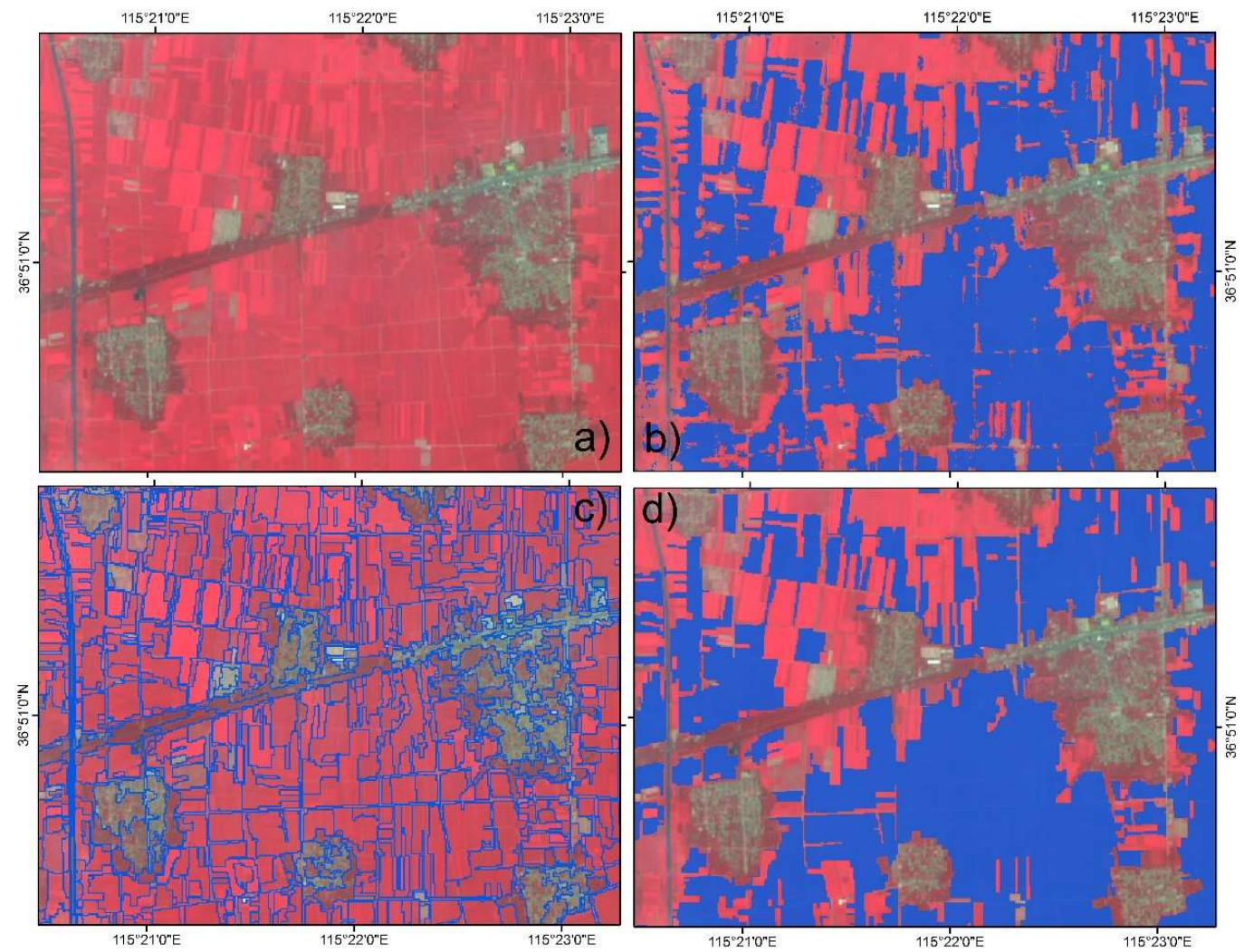

Figure 7. Part of the output images of object segmentation and integration with pixel-based results: (a) false-color combination with near infrared (NIR), red, and green in the R, G, and B channels, respectively; (b) pixel-based result output from a random forest (RF) classifier; (c) object boundary generated with multiresolution segmentation; and (d) integration with pixel-based results and object-oriented segmentation.

To remove the 'salt-and-pepper effect', the pixel-based result was integrated with object output from multiresolution segmentation to produce a fusion map. If all the pixels classified as corn within an object accounts for less than $50 \%$ of the area of that object, then the object will be dropped from the fusion map. Otherwise, the object will be labeled as corn. This approach excludes some very small objects and confusing scattered pixels misclassified as corn in areas of no corn (Figure $7 \mathrm{~b}, \mathrm{~d}$ ). 


\subsection{Accuracy Assessment}

To validate the fusion map that integrated the object segmentation and pixel-based classification results, field points and census data from the HEBEI Economic Yearbook 2017 were employed. User's accuracy (UA) and producer's accuracy (PA) were calculated using test points that were not involved in model training. In addition, the F1-Score, which is the harmonic average of the UA and PA, was calculated as follows:

$$
\mathrm{F} 1-\text { Score }=\frac{U A \times P A}{U A+P A} \times 2
$$

\section{Results}

\subsection{Optical and SAR Image Composites}

Figure 8 shows the differences in quantiles and the interval mean for each class extracted from all of the training points. Water is easily recognized in the NIR, SWIR2, SWIR2, VV, and VH bands. The urban values in three VI bands and the red and SWIR2 bands were separated from other classes, while the forest values in SWIR1, SWIR2, and NDVI show a clear distinction from the crop values. For crops, corn was different from other crops in the NIR, SWIR1, SIWR2, LSWI, NDVI, VV, and VH bands. The EVI band shows a distinction between vegetation and non-vegetation (water and urban), but less differentiation between corn and other vegetation.
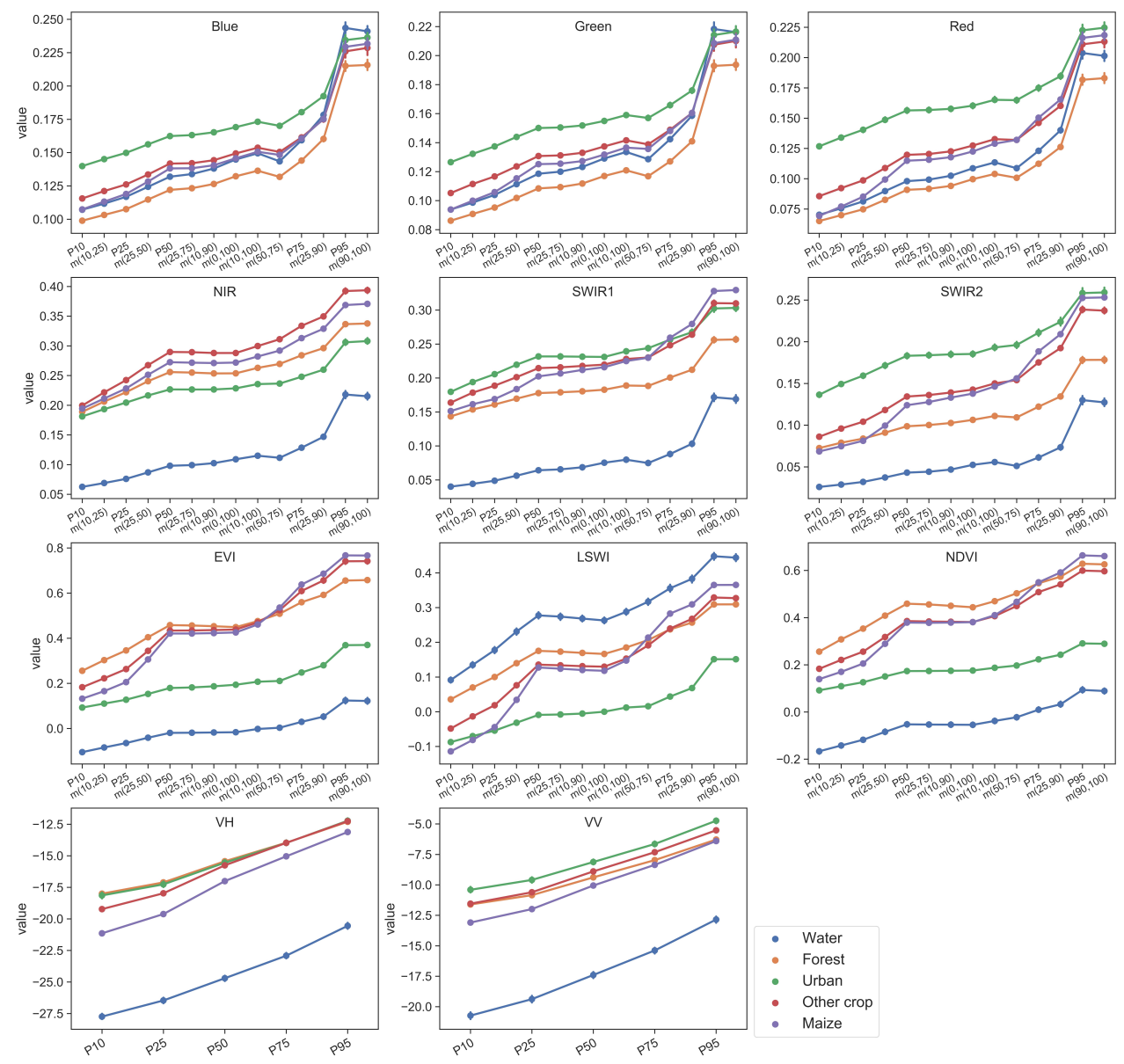

Figure 8. Quantiles and interval mean values of six optical bands, three VI bands, and two SAR bands for five classes. Each line is the average with $95 \%$ confidence intervals estimated for each class from all of the training points. 
The VV and VH bands reveal the same ability to distinguish corn and other crops in quantiles and interval mean metrics, although the VV band can discriminate corn in August and September, which is exhibited in monthly composites (Figure 9). The value of other crops was always higher than corn in the VH band, and this pattern was enhanced in June and October. In the VV band, corn and other crops peaked in July, and then corn decreased below the other crops in September.

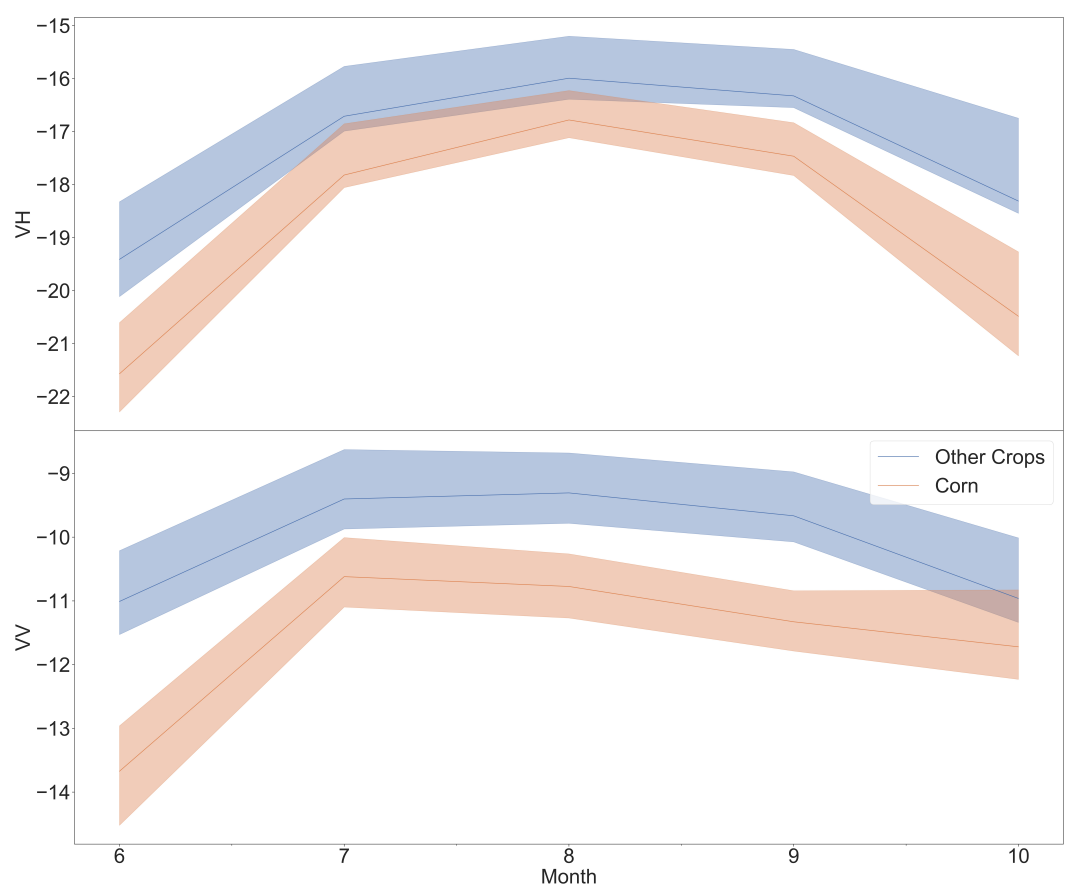

Figure 9. Median of the VV (Single co-polarization, vertical transmit/vertical receive) and VH (Dual-band cross-polarization, vertical transmit/horizontal receive) bands for monthly composites from all of the training points. Each line was filled with a $40-60 \%$ percentile deviation for each class.

\subsection{Corn Map of Hebei Province}

The Hebei Province corn map that integrated the pixel-based results generated with SAR, optical images in GEE, and object-based segmentation is shown in Figure 10. Spatially, corn was concentrated in southeastern Hebei Province, and characterized by a plains landform, which was sparse in the northern and western mountain areas (Figure 1). The detailed map exhibited two representative areas in Xingtai and Baoding. Corn was generally mixed with cotton in Xingtai (Figure 10c) and with sweet potato and forest in Baoding (Figure 10b).

Based on the field points that were not involved in model training, 870 field points of other crops and 911 points of corn were employed to validate the corn map. The confusion matrix and accuracy are listed in Table 1 . The corn category had a PA of $89.68 \%$ and UA of $90.48 \%$, while the F1-Score reached $89.70 \%$ and the overall accuracy achieved $89.89 \%$ throughout Hebei Province. The results indicate that corn can be accurately identified in a large area with optical and SAR images using the GEE platform. The PA, UA, and F1-Score for all of the prefecture-level cities are listed in Table 2. The F1-Score of corn ranged from $82.93 \%$ in Shijiazhuang to $95.11 \%$ in Cangzhou, while the other crop category varied from $78.05 \%$ in Baoding to $93.20 \%$ in Handan. 


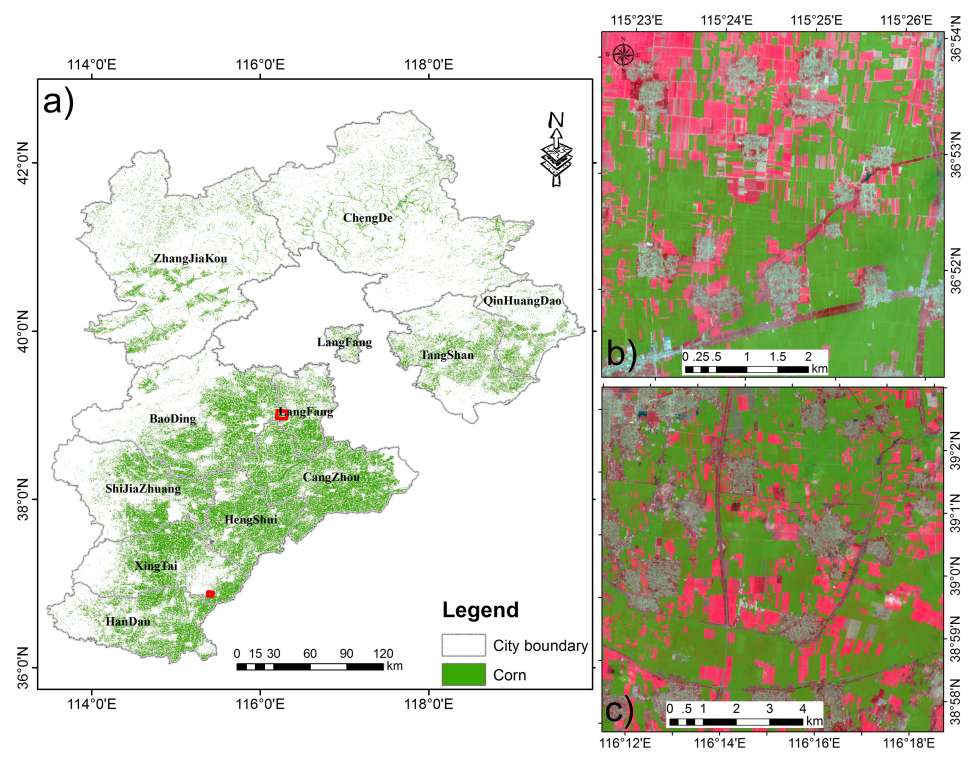

Figure 10. Corn map of Hebei Province, which integrates the pixel-based result generated with synthetic aperture radar (SAR), optical images in Google Earth Engine (GEE) and the object-based segmentation (a). The right column represents the detailed maps of Baoding (b) and Xingtai (c), and the specific location is labeled in (a) with two red rectangles.

Table 1. Testing point confusion matrix of the Hebei corn map.

\begin{tabular}{cccccc}
\hline \multirow{2}{*}{ Hebei Province } & \multicolumn{4}{c}{ Map Data } \\
\cline { 3 - 6 } & Other Crops & Corn & Total & Producer's Accuracy \\
\hline \multirow{3}{*}{ Field data } & Other Crops & 784 & 86 & 870 & $90.11 \%$ \\
& Corn & 94 & 817 & 911 & $89.68 \%$ \\
& Total & 878 & 903 & 1781 & \\
& User's Accuracy & $89.29 \%$ & $90.48 \%$ & & $89.89 \%$ \\
\hline
\end{tabular}

Table 2. Corn map accuracy in each prefecture-level city validated by the testing point.

\begin{tabular}{|c|c|c|c|c|}
\hline Region & Crop & Producer's Accuracy & User's Accuracy & F1-Score \\
\hline \multirow{2}{*}{ Baoding } & Other Crops & $82.05 \%$ & $74.42 \%$ & $78.05 \%$ \\
\hline & Corn & $92.57 \%$ & $95.14 \%$ & $93.84 \%$ \\
\hline \multirow{2}{*}{ Cangzhou } & Other Crops & $87.72 \%$ & $92.59 \%$ & $90.09 \%$ \\
\hline & Corn & $96.40 \%$ & $93.86 \%$ & $95.11 \%$ \\
\hline \multirow{2}{*}{ Chengde } & Other Crops & $86.67 \%$ & $90.28 \%$ & $88.44 \%$ \\
\hline & Corn & $86.27 \%$ & $81.48 \%$ & $83.81 \%$ \\
\hline \multirow{2}{*}{ Handan } & Other Crops & $92.31 \%$ & $94.12 \%$ & $93.20 \%$ \\
\hline & Corn & $88.10 \%$ & $84.73 \%$ & $86.38 \%$ \\
\hline \multirow{2}{*}{ Hengshui } & Other Crops & $85.81 \%$ & $86.93 \%$ & $86.36 \%$ \\
\hline & Corn & $88.57 \%$ & $87.57 \%$ & $88.07 \%$ \\
\hline \multirow{2}{*}{ Langfang } & Other Crops & $97.92 \%$ & $92.16 \%$ & $94.95 \%$ \\
\hline & Corn & $91.49 \%$ & $97.73 \%$ & $94.51 \%$ \\
\hline \multirow{2}{*}{ Qinhuangdao } & Other Crops & $80.36 \%$ & $90.00 \%$ & $84.91 \%$ \\
\hline & Corn & $90.20 \%$ & $80.70 \%$ & $85.19 \%$ \\
\hline \multirow{2}{*}{ Shijiazhuang } & Other Crops & $84.85 \%$ & $93.33 \%$ & $88.89 \%$ \\
\hline & Corn & $89.47 \%$ & $77.27 \%$ & $82.93 \%$ \\
\hline \multirow{2}{*}{ Tangshan } & Other Crops & $90.91 \%$ & $90.91 \%$ & $90.91 \%$ \\
\hline & Corn & $90.00 \%$ & $90.00 \%$ & $90.00 \%$ \\
\hline \multirow{2}{*}{ Xingtai } & Other Crops & $95.38 \%$ & $83.22 \%$ & $88.89 \%$ \\
\hline & Corn & $79.51 \%$ & $94.17 \%$ & $86.22 \%$ \\
\hline \multirow{2}{*}{ Zhangjiakou } & Other Crops & $90.00 \%$ & $96.43 \%$ & $93.10 \%$ \\
\hline & Corn & $93.75 \%$ & $83.33 \%$ & $88.24 \%$ \\
\hline
\end{tabular}




\subsection{Comparison before and after Integration}

To examine the integration effect with object segmentation, the corn area before and after integration in the prefecture-level city was compared with the census area obtained from the HEBEI Economic Yearbook 2017. The corn area was estimated by subtracting the summer harvest grain area from the cereal area, because the corn area for each city is unavailable, and the cereal area primarily contains the corn and winter wheat that are harvested in summer. The scatter figure comparing the corn area predicted in this research with the census data at each prefecture-level city is shown in Figure 11. After obtaining the integration segmentation results and pixel-based classification results, during which the misclassified pixel and small-scale noise were removed, the corn area results were closer to the census data. The results showed that the corn area estimated from the optical and SAR images correlated well with the census data, with an $R^{2}=0.91$ and a root mean square error (RMSE) of $470.90 \mathrm{~km}^{2}$. Additionally, due to the integration, the corn area consistently decreases regardless of degree, which may be a result of an unbalanced distribution of classified pixels within objects whose interiors are heterogeneous.

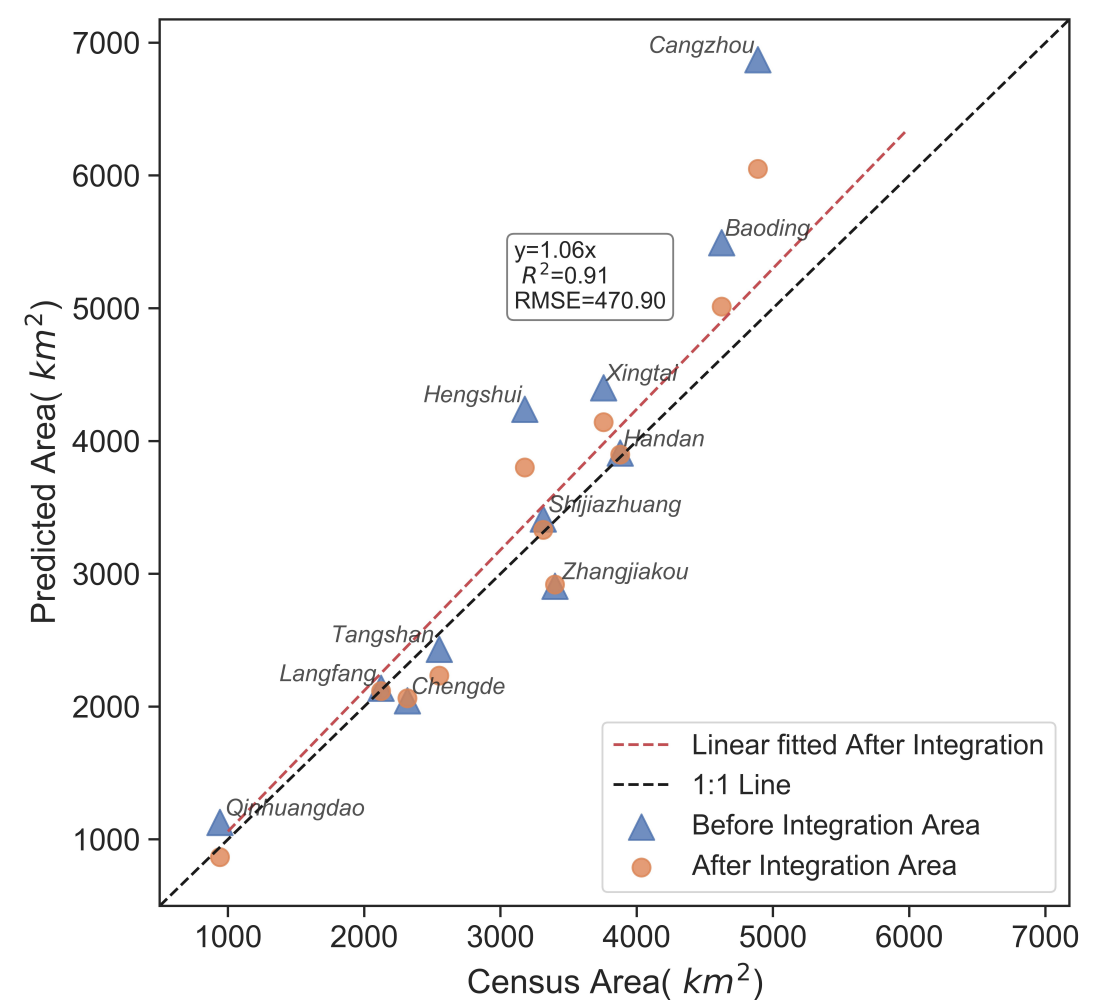

Figure 11. Comparison of the corn area predicted in this research and the census data for each prefecture-level city. The census data were obtained from the HEBEI Economic Yearbook 2017, and the corn area was estimated by subtracting the summer harvest grain area from the cereal area.

\subsection{Contribution of the Features to Classification}

To explore the contribution of specific variables to corn mapping, we conducted an RF experiment using the Scikit-learn package [70] in Python, and exported the feature importance (Figure 12), because the RF classifier in the GEE platform cannot run a variable importance metric. The value of feature importance denotes the error increase in the OOB when a feature was excluded during a permutation of features. In the SAR compositing features, the $25^{\text {th }}$ percentile of the $\mathrm{VH}$ band was the most important feature, followed by the $50^{\text {th }}$ percentile and $75^{\text {th }}$ percentile of the VH band. The NDVI interval mean value between the $75^{\text {th }}$ and $90^{\text {th }}$ percentiles was the most important feature, followed by the $25^{\text {th }}$ percentile of SWIR1. Summarizing all of the band metrics, the NIR is a paramount band and accounts for $16.1 \%$, followed by the NDVI, which accounts for $15.4 \%$; the SWIR1, which accounts for $14.5 \%$; and 
the SWIR2, which accounts for $11.1 \%$ overall. Although the SWIR bands have not been widely used in crop-type classifications, SWIR bands play a major role in corn classification, are related to crop water content [71], and can be used to identify crop types [53] and estimate crop yields [72].

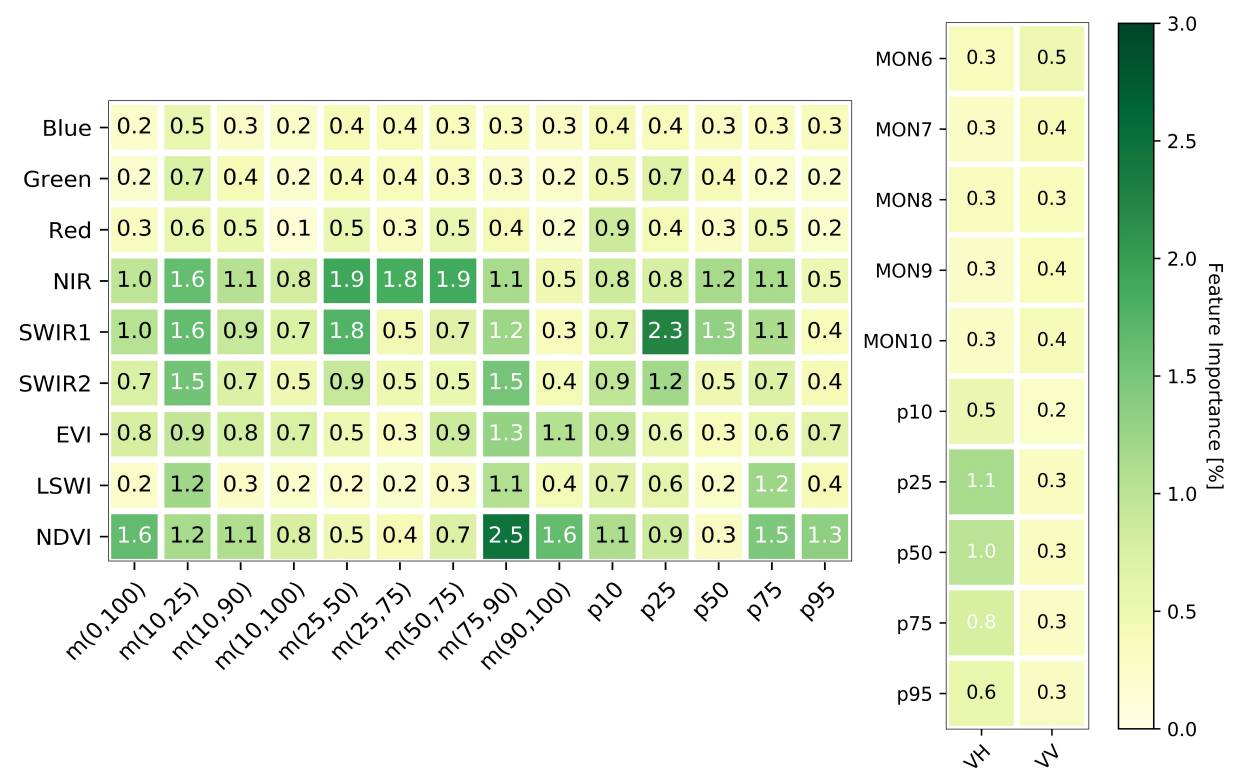

Figure 12. Importance of the features generated in the RF classifier indicating an error increase for 'out-of-bag' (OOB) samples when a feature was removed. Here, the RF classifier was applied in the Scikit-learn package of Python [70]. The importance value was averaged for 10 cross-validations. The normalized differenced vegetation index (NDVI) interval mean value between the $75^{\text {th }}$ and $90^{\text {th }}$ percentiles was the most important feature, and the NIR was the foremost band, with an overall importance of $16.1 \%$.

\section{Discussion}

\subsection{Reliability of Corn Mapping Using Optical and SAR Images in GEE}

Corn was well identified in Hebei Province using optical and SAR image metric composites in GEE and integrating the results with object-based segmentation. Compared with previous crop-type identification studies at large scales for practical crop monitoring, which used 250-m to 30-m spatial resolutions, this study represents an important attempt to map corn at a $10-\mathrm{m}$ resolution at the province scale. The success of this research was attributed to the aggregation of data sources, efficient platforms, and advanced machine learning algorithms.

The aggregation of Sentinel-2 and Sentinel-1 data provides important information for corn mapping in Hebei Province, which can be concluded from the comparison of F1-Scores between different feature combinations as input (Figure 13). Compared with using all of the features as input, one group contains only Sentinel-2 image metric composites, while the other group includes Sentinel-1 metric composites of the VV and VH bands. The F1-Scores of all the features as input, including optical and SAR image metric composites, was the highest in the three groups. The F1-Score of the group that contained only optical image metric composites was slightly lower. 


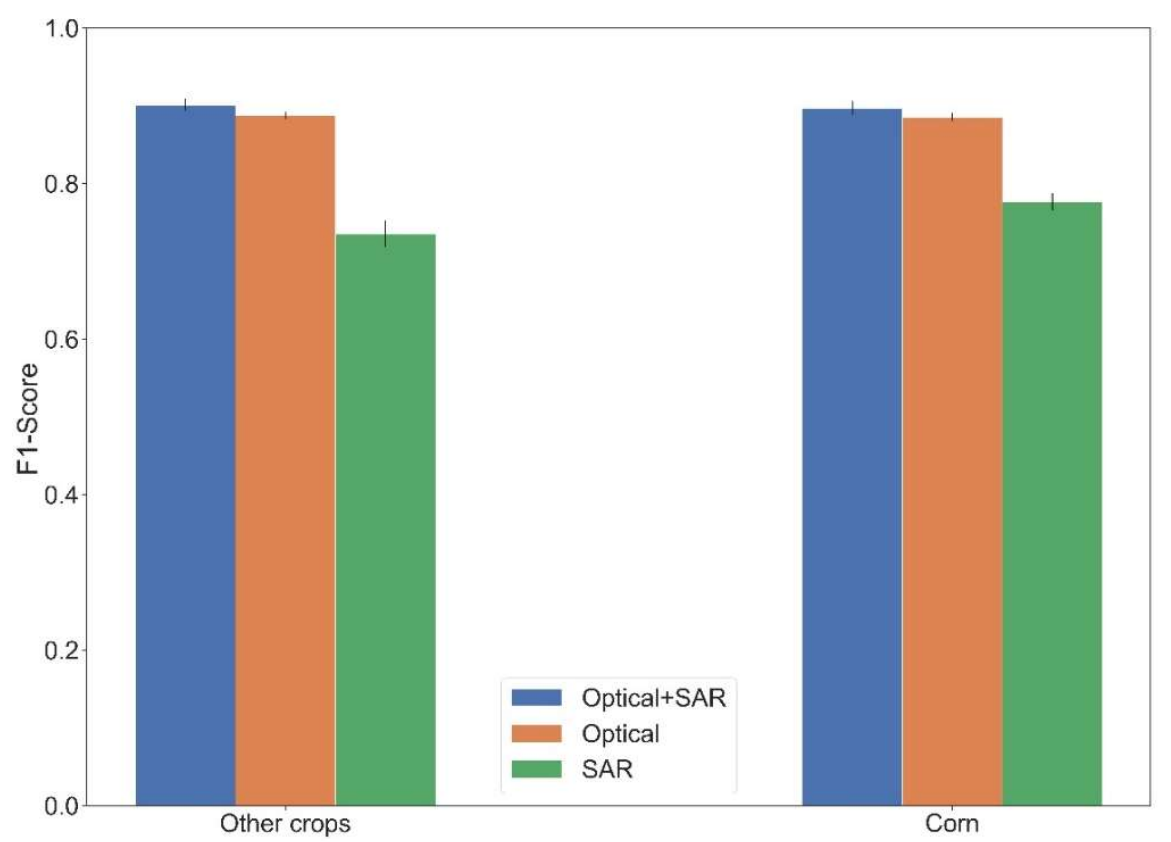

Figure 13. Comparison of F1-Scores among different variable combinations. Three groups of features were tested. Compared with using all of the features as input, one group contains only optical image metric composites, while the other group includes SAR metric composites of the VV and VH bands.

After the Sentinel-2B satellite delivered the first images on 15 June [73], the Sentinel-2 constellation was commissioned, providing a higher spatial resolution of $10 \mathrm{~m}$ and temporal resolution of five days for mapping corn with previous data sources. Compared with Landsat 8, which has an average of 36.4 observations in northeastern Asia for all of 2014 [10], the Sentinel-2 constellation observed Hebei Province 40.6 times in five months from June to October. The number of good observations from the Sentinel-2 constellation was 21.9 on average in less than half a year (Figure 14), while the frequency of Landsat 8 was only 20.3 for the entire year [10]. As shown in Figure 14, the number of good observations was spatially inhomogeneous and ranged from three times to 192 times. Although the Sentinel-2 constellation had 10 15 observations in $27.0 \%$ of the total area and 15 20 observations in $17.8 \%$ of the entire study area, Sentinel- 2 revisited 3.0\% of Hebei Province on clear days less than five times. The Sentinel-1 images, which were shown to be capable of crop classification [15,18], can provide additional information for corn mapping in these regions, despite the F1-Score of the group containing only SAR image metric composites that were lower than F1-Score of the group using all of the features as input (Figure 13).

The combination of image metric composites and RFs performed well in mapping corn. Compared with MODIS, which produced eight-day/16-day/one-month composites, medium to high-resolution images, such as Landsat 7 and 8 and Sentinel-2, were not composited during the fixed period due to an indeterminacy of good observation times. These metric composites, including the percentile and interval mean composites, can capture important characteristics [8] and interpret images acquired on clear days by a number of metrics, which achieved a high level of accuracy in forest mapping [46,62] and crop-type mapping [1,8].

Based on cloud computing, the GEE platform efficiently processed and composited thousands of imagery scenes. After importing the Sentinel-1/2 images archived in GEE, the metric compositing, training, and application of the RF classifier to output the corn map takes only $\sim 10 \mathrm{~h}$ at the province scale. This GEE efficiency shown in corn mapping on a large scale is consistent with that of cloud computing-based classifications of land cover and crop type, and will represent a new paradigm in the future [50]. To avoid the 'salt-and-pepper effect', we conducted object segmentation in eCognition 9.2 with the aid of the ESP tool and integrated object segmentation with the pixel-based classification 
result. The results show improved consistency with the census data, which is consistent with Massey et al., who integrated pixel-based cropland and object-based segmentation and obtained higher accuracy [74].

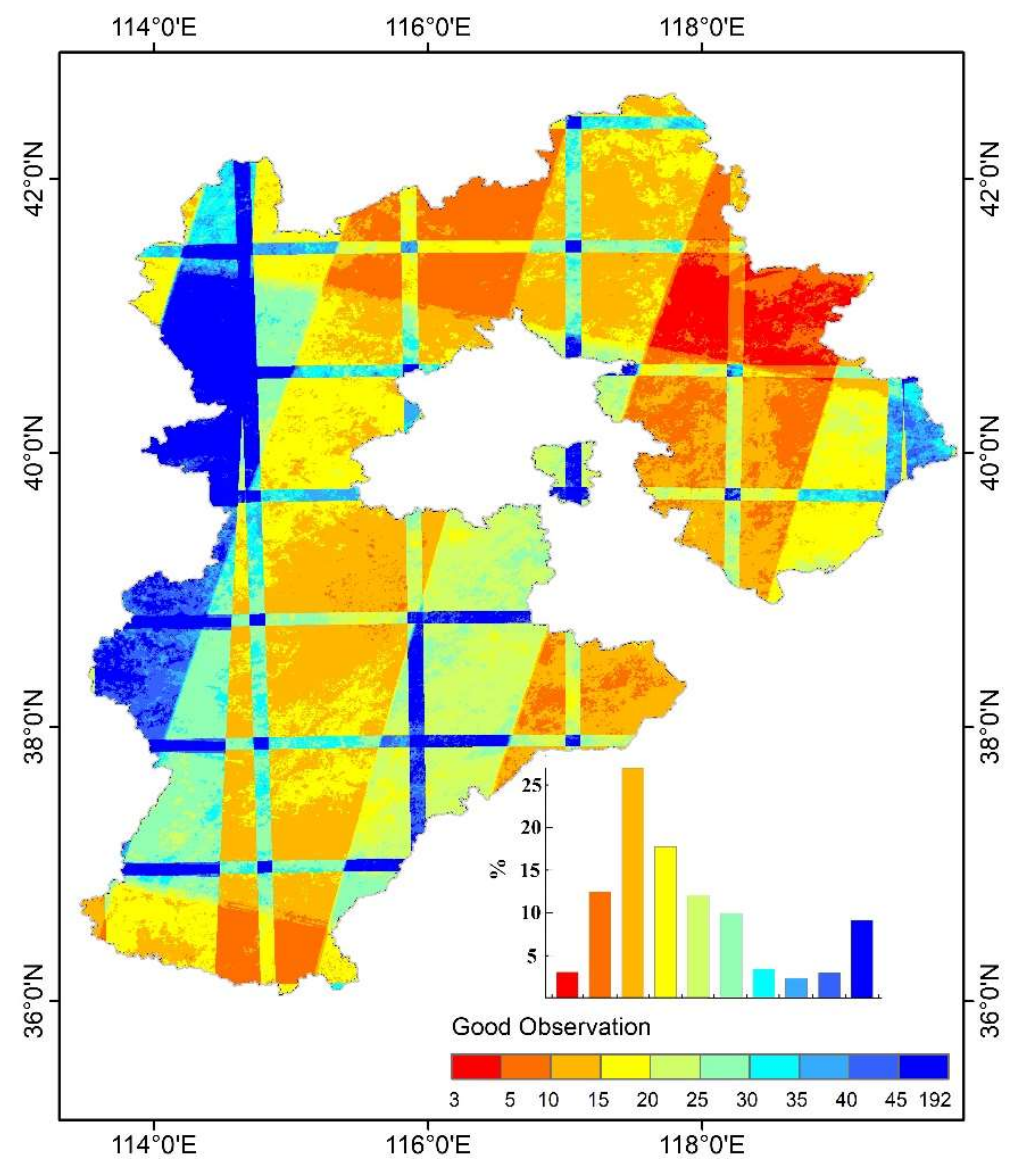

Figure 14. Number of good observations between June and October 2017 by masking opaque and cirrus clouds. The embedded histogram shows the distribution of Sentinel-2 imagery number with different color bars, and the color is the same as the map legends.

\subsection{Uncertainty Analysis and Outlook}

In this research, optical image and SAR image metric composites were used as input in the RF classifier, and a high level of accuracy was realized in corn mapping. We used TOA reflectance as a substitute for surface reflectance (SR) in the Sentinel-2 data, and the effect of the atmosphere was not available until after this research was complete. The substitution may have affected the classification results. Although the acceptable accuracy shows a limited effect, the EVI obtained from the TOA reflectance will be higher than the true value [10]. A comparison between TOA reflectance and SR is recommended in the future to determine the effects. Additionally, the Sen2-Agri tool can be used to produce cloud-free SR composites [34].

The corn map generated with only SAR image metric composites was subject to the 'salt-and-pepper effect' (Figure 15a) due to the speckle perturbation in the SAR images [43]. Although this phenomenon can be eliminated (Figure 15b) when optical metric features are more than SAR metrics features, the 'salt-and-pepper effect' will be acute when the approach introduced in this research is applied to the areas without sufficient cloud-free optical images, such as tropical regions. 

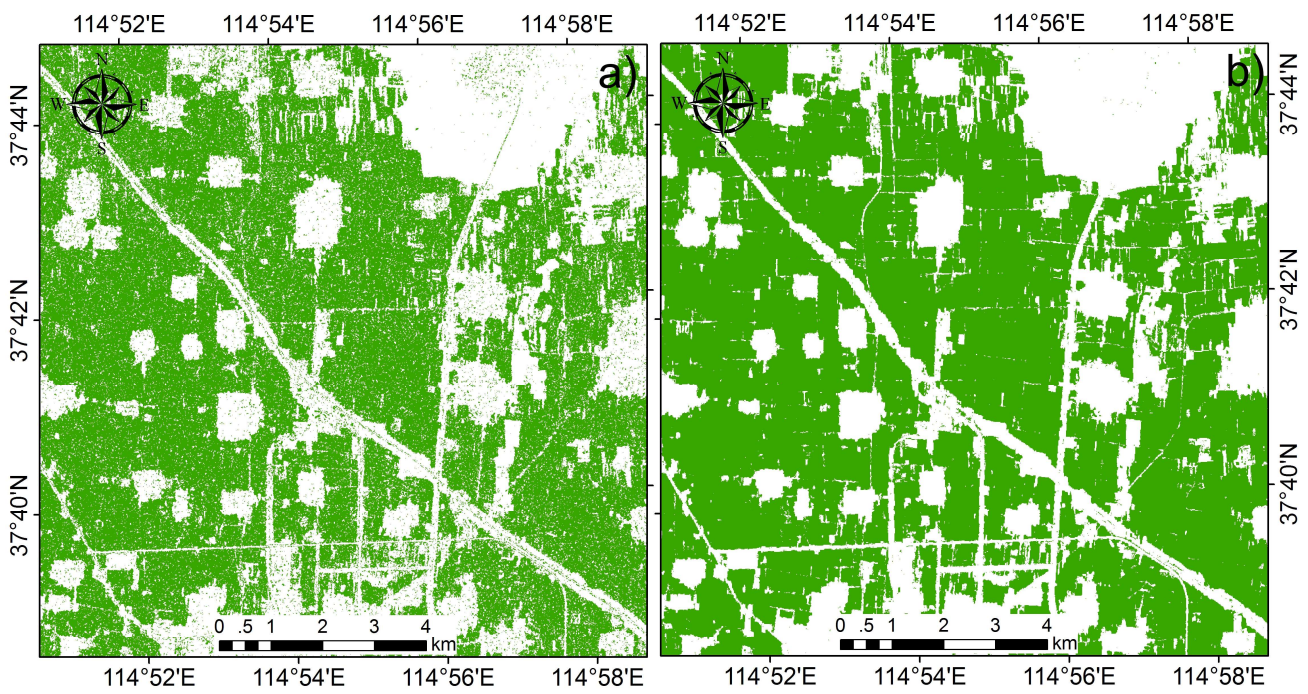

Figure 15. Comparison between the pixel-based classification result using only synthetic aperture radar (SAR) image metric composites (a) and optical and SAR image metric composites (b) as input. The corn map generated with only SAR image metric composites was subject to the speckle effect. Combined with optical images, this phenomenon can be constrained.

With advancements in deep learning technology, more powerful machine learning methods can be introduced for crop identification. A long short-term memory (LSTM) neural network, which is a type of recurrent neural network, made important progress in speech recognition [75], which discriminates words in a sequence of acoustic signals. The time series image sequence for different crops is less complicated than the acoustic signal sequence [76]. Implementing LSTM to identify crops would be expected to generate crop-type maps with a higher level of accuracy.

\section{Conclusions}

Most existing corn mapping methods use coarse resolution and seldom use high-resolution images on a large scale. Mapping crop types with coarse resolution imagery leads to problems with mixed pixels and cannot reflect detailed information on a field scale. High-resolution SAR and optical images with a 10-m resolution enable us to depict corn distributions in detail, and can be applied on a large scale with the assistance of cloud computing technology.

This research demonstrated a cloud computing-based approach for the identification of corn cultivated areas at a 10-m resolution using Sentinel-2 and Sentinel-1 images. Certain metric composites were calculated, including monthly composites and percentile composites for Sentinel-1 images and percentile and interval mean composites for Sentinel-2 images, which were used as input to the RF algorithm in the GEE platform. To avoid the 'salt-and-pepper effect', object segmentation was implemented in eCognition software with the assistance of the ESP tool. After integrating the pixel-based result generated from RF and object segmentation, the corn's F1-Score reached $90.08 \%$, and the overall accuracy was $89.89 \%$. The acceptable accuracy suggests that the approach introduced in this research is reliable for corn mapping. The combination of SAR images and optical images improved the accuracy of SAR images and provided additional information for areas without sufficient optical images. The metric composites and RF classifier were implemented in the GEE platform and completed within one day, suggesting that the cloud computing platform facilitates corn mapping efficiency and ensures the practicability of the approach introduced in this research.

Author Contributions: F.T. contributed to the research experiments and wrote the paper. B.W. conceived this research and was responsible for the research. X.Z., H.Z., and J.X. collected and preprocessed the original data. All of the co-authors helped polish the manuscript. 
Funding: This research was funded by the Strategic Priority Research Program of the Chinese Academy of Sciences (XDA19030201), the National Key Research and Development Program (2016YFA0600304), and the National Natural Science Foundation of China (41561144013).

Acknowledgments: We thank the anonymous reviewers for reviewing the manuscript and providing comments to improve the manuscript.

Conflicts of Interest: The authors declare that they have no conflicts of interest to disclose.

\section{References}

1. Zhang, X.; Wu, B.; Ponce-Campos, G.; Zhang, M.; Chang, S.; Tian, F. Mapping up-to-date paddy rice extent at $10 \mathrm{~m}$ resolution in china through the integration of optical and synthetic aperture radar images. Remote Sens. 2018, 10, 1200. [CrossRef]

2. Zhong, L.; Gong, P.; Biging, G.S. Efficient corn and soybean mapping with temporal extendability: A multi-year experiment using landsat imagery. Remote Sens. Environ. 2014, 140, 1-13. [CrossRef]

3. Griggs, D.; Stafford-Smith, M.; Gaffney, O.; Rockström, J.; Öhman, M.C.; Shyamsundar, P.; Steffen, W.; Glaser, G.; Kanie, N.; Noble, I. Policy: Sustainable development goals for people and planet. Nature 2013, 495, 305. [CrossRef]

4. Wu, B.; Yan, N.; Xiong, J.; Bastiaanssen, W.G.M.; Zhu, W.; Stein, A. Validation of ETWatch using field measurements at diverse landscapes: A case study in Hai basin of china. J. Hydrol. 2012, 436-437, 67-80. [CrossRef]

5. Yan, N.; Wu, B.; Perry, C.; Zeng, H. Assessing potential water savings in agriculture on the Hai basin plain, china. Agric. Water Manag. 2015, 154, 11-19. [CrossRef]

6. Zhang, J.; Feng, L.; Yao, F. Improved maize cultivated area estimation over a large scale combining modis-evi time series data and crop phenological information. ISPRS J. Photogramm. Remote Sens. 2014, 94, 102-113. [CrossRef]

7. Zwart, S.J.; Bastiaanssen, W.G.M. Review of measured crop water productivity values for irrigated wheat, rice, cotton and maize. Agric. Water Manag. 2004, 69, 115-133. [CrossRef]

8. Song, X.-P.; Potapov, P.V.; Krylov, A.; King, L.; Di Bella, C.M.; Hudson, A.; Khan, A.; Adusei, B.; Stehman, S.V.; Hansen, M.C. National-scale soybean mapping and area estimation in the united states using medium resolution satellite imagery and field survey. Remote Sens. Environ. 2017, 190, 383-395. [CrossRef]

9. Gao, F.; Anderson, M.C.; Zhang, X.; Yang, Z.; Alfieri, J.G.; Kustas, W.P.; Mueller, R.; Johnson, D.M.; Prueger, J.H. Toward mapping crop progress at field scales through fusion of landsat and MODIS imagery. Remote Sens. Environ. 2017, 188, 9-25. [CrossRef]

10. Dong, J.; Xiao, X.; Menarguez, M.A.; Zhang, G.; Qin, Y.; Thau, D.; Biradar, C.; Moore, B., 3rd. Mapping paddy rice planting area in northeastern Asia with landsat 8 images, phenology-based algorithm and google earth engine. Remote Sens. Environ. 2016, 185, 142-154. [CrossRef]

11. Wardlow, B.; Egbert, S.; Kastens, J. Analysis of time-series Modis $250 \mathrm{~m}$ vegetation index data for crop classification in the U.S. Central great plains. Remote Sens. Environ. 2007, 108, 290-310. [CrossRef]

12. Wu, B.; Li, Q. Crop planting and type proportion method for crop acreage estimation of complex agricultural landscapes. Int. J. Appl. Earth Obs. Geoinf. 2012, 16, 101-112. [CrossRef]

13. Immitzer, M.; Vuolo, F.; Atzberger, C. First experience with sentinel-2 data for crop and tree species classifications in central Europe. Remote Sens. 2016, 8, 166. [CrossRef]

14. Zeng, L.; Wardlow, B.D.; Wang, R.; Shan, J.; Tadesse, T.; Hayes, M.J.; Li, D. A hybrid approach for detecting corn and soybean phenology with time-series MODIS data. Remote Sens. Environ. 2016, 181, 237-250. [CrossRef]

15. Bargiel, D. A new method for crop classification combining time series of radar images and crop phenology information. Remote Sens. Environ. 2017, 198, 369-383. [CrossRef]

16. Peña-Barragán, J.M.; Ngugi, M.K.; Plant, R.E.; Six, J. Object-based crop identification using multiple vegetation indices, textural features and crop phenology. Remote Sens. Environ. 2011, 115, 1301-1316. [CrossRef]

17. Larrañaga, A.; Álvarez-Mozos, J. On the added value of Quad-Pol Data in a multi-temporal crop classification framework based on RADARSAT-2 imagery. Remote Sens. 2016, 8, 335. [CrossRef] 
18. Mascolo, L.; Lopez-Sanchez, J.M.; Vicente-Guijalba, F.; Nunziata, F.; Migliaccio, M.; Mazzarella, G. A complete procedure for crop phenology estimation with PolSAR data based on the complex Wishart classifier. IEEE Trans. Geosci. Remote Sens. 2016, 54, 6505-6515. [CrossRef]

19. Wardlow, B.D.; Egbert, S.L. Large-area crop mapping using time-series MODIS $250 \mathrm{~m}$ NDVI data: An assessment for the U.S. Central great plains. Remote Sens. Environ. 2008, 112, 1096-1116. [CrossRef]

20. Estel, S.; Kuemmerle, T.; Alcántara, C.; Levers, C.; Prishchepov, A.; Hostert, P. Mapping farmland abandonment and recultivation across Europe using MODIS NDVI time series. Remote Sens. Environ. 2015, 163, 312-325. [CrossRef]

21. Pan, Z.; Huang, J.; Zhou, Q.; Wang, L.; Cheng, Y.; Zhang, H.; Blackburn, G.A.; Yan, J.; Liu, J. Mapping crop phenology using NDVI time-series derived from HJ-1 A/B data. Int. J. Appl. Earth Obs. Geoinf. 2015, 34, 188-197. [CrossRef]

22. Estel, S.; Kuemmerle, T.; Levers, C.; Baumann, M.; Hostert, P. Mapping cropland-use intensity across Europe using MODIS NDVI time series. Environ. Res. Lett. 2016, 11, 024015. [CrossRef]

23. Zhang, G.; Xiao, X.; Dong, J.; Kou, W.; Jin, C.; Qin, Y.; Zhou, Y.; Wang, J.; Menarguez, M.A.; Biradar, C. Mapping paddy rice planting areas through time series analysis of MODIS land surface temperature and vegetation index data. ISPRS J. Photogramm. Remote Sens. 2015, 106, 157-171. [CrossRef]

24. Arvor, D.; Jonathan, M.; Meirelles, M.S.P.; Dubreuil, V.; Durieux, L. Classification of modis evi time series for crop mapping in the state of Mato Grosso, brazil. Int. J. Remote Sens. 2011, 32, 7847-7871. [CrossRef]

25. Skakun, S.; Franch, B.; Vermote, E.; Roger, J.-C.; Becker-Reshef, I.; Justice, C.; Kussul, N. Early season large-area winter crop mapping using MODIS NDVI data, growing degree days information and a gaussian mixture model. Remote Sens. Environ. 2017, 195, 244-258. [CrossRef]

26. Lee, E.; Kastens, J.H.; Egbert, S.L. Investigating collection 4 versus collection 5 MODIS 250 m NDVI time-series data for crop separability in Kansas, USA. Int. J. Remote Sens. 2016, 37, 341-355. [CrossRef]

27. Massey, R.; Sankey, T.T.; Congalton, R.G.; Yadav, K.; Thenkabail, P.S.; Ozdogan, M.; Sánchez Meador, A.J. Modis phenology-derived, multi-year distribution of conterminous U.S. Crop types. Remote Sens. Environ. 2017, 198, 490-503. [CrossRef]

28. Löw, F.; Prishchepov, A.; Waldner, F.; Dubovyk, O.; Akramkhanov, A.; Biradar, C.; Lamers, J. Mapping cropland abandonment in the Aral Sea Basin with MODIS time series. Remote Sens. 2018, 10, 159. [CrossRef]

29. De Wit, A.J.W.; Clevers, J.G.P.W. Efficiency and accuracy of per-field classification for operational crop mapping. Int. J. Remote Sens. 2004, 25, 4091-4112. [CrossRef]

30. Zheng, B.; Myint, S.W.; Thenkabail, P.S.; Aggarwal, R.M. A support vector machine to identify irrigated crop types using time-series Landsat NDVI data. Int. J. Appl. Earth Obs. Geoinf. 2015, 34, 103-112. [CrossRef]

31. Vieira, M.A.; Formaggio, A.R.; Rennó, C.D.; Atzberger, C.; Aguiar, D.A.; Mello, M.P. Object based image analysis and data mining applied to a remotely sensed Landsat time-series to map sugarcane over large areas. Remote Sens. Environ. 2012, 123, 553-562. [CrossRef]

32. Schultz, B.; Immitzer, M.; Formaggio, A.; Sanches, I.; Luiz, A.; Atzberger, C. Self-guided segmentation and classification of multi-temporal Landsat 8 images for crop type mapping in southeastern brazil. Remote Sens. 2015, 7, 14482-14508. [CrossRef]

33. Kontgis, C.; Schneider, A.; Ozdogan, M. Mapping rice paddy extent and intensification in the vietnamese mekong river delta with dense time stacks of Landsat data. Remote Sens. Environ. 2015, 169, 255-269. [CrossRef]

34. Bontemps, S.; Arias, M.; Cara, C.; Dedieu, G.; Guzzonato, E.; Hagolle, O.; Inglada, J.; Matton, N.; Morin, D.; Popescu, R.; et al. Building a data set over 12 globally distributed sites to support the development of agriculture monitoring applications with sentinel-2. Remote Sens. 2015, 7, 16062-16090. [CrossRef]

35. Inglada, J.; Arias, M.; Tardy, B.; Hagolle, O.; Valero, S.; Morin, D.; Dedieu, G.; Sepulcre, G.; Bontemps, S.; Defourny, P.; et al. Assessment of an operational system for crop type map production using high temporal and spatial resolution satellite optical imagery. Remote Sens. 2015, 7, 12356-12379. [CrossRef]

36. Matton, N.; Canto, G.; Waldner, F.; Valero, S.; Morin, D.; Inglada, J.; Arias, M.; Bontemps, S.; Koetz, B.; Defourny, P. An automated method for annual cropland mapping along the season for various globally-distributed agrosystems using high spatial and temporal resolution time series. Remote Sens. 2015, 7, 13208-13232. [CrossRef] 
37. Valero, S.; Morin, D.; Inglada, J.; Sepulcre, G.; Arias, M.; Hagolle, O.; Dedieu, G.; Bontemps, S.; Defourny, P.; Koetz, B. Production of a dynamic cropland mask by processing remote sensing image series at high temporal and spatial resolutions. Remote Sens. 2016, 8, 55. [CrossRef]

38. Skriver, H. Crop classification by multitemporal C- and L-band single- and dual-polarization and fully polarimetric SAR. IEEE Trans. Geosci. Remote Sens. 2012, 50, 2138-2149. [CrossRef]

39. Freeman, A.; Villasenor, J.; Klein, J.; Hoogeboom, P.; Groot, J. On the use of multi-frequency and polarimetric radar backscatter features for classification of agricultural crops. Int. J. Remote Sens. 1994, 15, 1799-1812. [CrossRef]

40. Schmullius, C.; Schrage, T. Classification, Crop Parameter Estimation and Synergy Effects Using Airborne DLR E-SAR and DAEDALUS Images. In Proceedings of the 1998 IEEE International Geoscience and Remote Sensing Symposium, IGARSS'98, Seattle, WA, USA, 6-10 July 1998; pp. 97-99.

41. Lee, J.-S.; Grunes, M.R.; Pottier, E. Quantitative comparison of classification capability: Fully polarimetric versus dual and single-polarization SAR. IEEE Trans. Geosci. Remote Sens. 2001, 39, 2343-2351.

42. Del Frate, F.; Schiavon, G.; Solimini, D.; Borgeaud, M.; Hoekman, D.H.; Vissers, M.A. Crop classification using multiconfiguration C-band SAR data. IEEE Trans. Geosci. Remote Sens. 2003, 41, 1611-1619. [CrossRef]

43. Jia, K.; Li, Q.; Tian, Y.; Wu, B.; Zhang, F.; Meng, J. Crop classification using multi-configuration SAR data in the north china plain. Int. J. Remote Sens. 2011, 33, 170-183. [CrossRef]

44. McNairn, H.; Shang, J.; Jiao, X.; Champagne, C. The contribution of ALOS PALSAR multipolarization and polarimetric data to crop classification. IEEE Trans. Geosci. Remote Sens. 2009, 47, 3981-3992. [CrossRef]

45. Gorelick, N.; Hancher, M.; Dixon, M.; Ilyushchenko, S.; Thau, D.; Moore, R. Google earth engine: Planetary-scale geospatial analysis for everyone. Remote Sens. Environ. 2017, 202, 18-27. [CrossRef]

46. Hansen, M.C.; Potapov, P.V.; Moore, R.; Hancher, M.; Turubanova, S.; Tyukavina, A.; Thau, D.; Stehman, S.; Goetz, S.; Loveland, T. High-resolution global maps of 21st-century forest cover change. Science 2013, 342, 850-853. [CrossRef]

47. Patel, N.N.; Angiuli, E.; Gamba, P.; Gaughan, A.; Lisini, G.; Stevens, F.R.; Tatem, A.J.; Trianni, G. Multitemporal settlement and population mapping from Landsat using google earth engine. Int. J. Appl. Earth Obs. Geoinf. 2015, 35, 199-208. [CrossRef]

48. Xiong, J.; Thenkabail, P.S.; Gumma, M.K.; Teluguntla, P.; Poehnelt, J.; Congalton, R.G.; Yadav, K.; Thau, D. Automated cropland mapping of continental Africa using google earth engine cloud computing. ISPRS J. Photogramm. Remote Sens. 2017, 126, 225-244. [CrossRef]

49. Goldblatt, R.; You, W.; Hanson, G.; Khandelwal, A. Detecting the boundaries of urban areas in india: A dataset for pixel-based image classification in google earth engine. Remote Sens. 2016, 8, 634. [CrossRef]

50. Azzari, G.; Lobell, D.B. Landsat-based classification in the cloud: An opportunity for a paradigm shift in land cover monitoring. Remote Sens. Environ. 2017, 202, 64-74. [CrossRef]

51. Huang, H.; Chen, Y.; Clinton, N.; Wang, J.; Wang, X.; Liu, C.; Gong, P.; Yang, J.; Bai, Y.; Zheng, Y.; et al. Mapping major land cover dynamics in Beijing using all Landsat images in google earth engine. Remote Sens. Environ. 2017, 202, 166-176. [CrossRef]

52. National Bureau of Statistics of China. National Data. Available online: http:// data.stats.gov.cn/easyquery. htm?cn=E0103\&zb=A0D0P\&reg=130000\&sj=2016 (accessed on 22 October 2018).

53. Cai, Y.; Guan, K.; Peng, J.; Wang, S.; Seifert, C.; Wardlow, B.; Li, Z. A high-performance and in-season classification system of field-level crop types using time-series Landsat data and a machine learning approach. Remote Sens. Environ. 2018, 210, 35-47. [CrossRef]

54. Tucker, C.J. Red and photographic infrared linear combinations for monitoring vegetation. Remote Sens. Environ. 1979, 8, 127-150. [CrossRef]

55. Huete, A.; Didan, K.; Miura, T.; Rodriguez, E.P.; Gao, X.; Ferreira, L.G. Overview of the radiometric and biophysical performance of the MODIS vegetation indices. Remote Sen. Environ. 2002, 83, 195-213. [CrossRef]

56. Xiao, X.; Boles, S.; Liu, J.; Zhuang, D.; Liu, M. Characterization of forest types in Northeastern China, using multi-temporal spot-4 vegetation sensor data. Remote Sens. Environ. 2002, 82, 335-348. [CrossRef]

57. Sellers, P.; Berry, J.; Collatz, G.; Field, C.; Hall, F. Canopy reflectance, photosynthesis, and transpiration. III. A reanalysis using improved leaf models and a new canopy integration scheme. Remote Sens. Environ. 1992, 42, 187-216. [CrossRef]

58. Veci, L. Sentinel-1 Toolbox; SAR Basics Tutoria; Array Systems Computing Inc.: North York, ON, Canada, 2016. 
59. RADI. Gvg for Android. Available online: https://play.google.com/store/apps/details?id=com.sysapk. gvg\&hl=en_US (accessed on 29 October 2018).

60. Benediktsson, J.A.; Swain, P.H.; Ersoy, O.K. Neural network approaches versus statistical methods in classification of multisource remote sensing data. In Proceedings of the 12th Canadian Symposium on Remote Sensing Geoscience and Remote Sensing Symposium, Vancouver, BC, Canada, 6-10 July 1990.

61. Blaschke, T. Object based image analysis for remote sensing. ISPRS J. Photogramm. Remote Sens. 2010, 65, 2-16. [CrossRef]

62. Potapov, P.V.; Turubanova, S.A.; Hansen, M.C.; Adusei, B.; Broich, M.; Altstatt, A.; Mane, L.; Justice, C.O. Quantifying forest cover loss in democratic republic of the Congo, 2000-2010, with Landsat ETM+ data. Remote Sens. Environ. 2012, 122, 106-116. [CrossRef]

63. Breiman, L. Random forests. Mach. Learn. 2001, 45, 5-32. [CrossRef]

64. Belgiu, M.; Drăguț, L. Random forest in remote sensing: A review of applications and future directions. ISPRS J. Photogramm. Remote Sens. 2016, 114, 24-31. [CrossRef]

65. Yan, J.; Lin, L.; Zhou, W.; Ma, K.; Pickett, S.T.A. A novel approach for quantifying particulate matter distribution on leaf surface by combining SEM and object-based image analysis. Remote Sens. Environ. 2016, 173, 156-161. [CrossRef]

66. Lu, M.; Chen, J.; Tang, H.; Rao, Y.; Yang, P.; Wu, W. Land cover change detection by integrating object-based data blending model of Landsat and MODIS. Remote Sens. Environ. 2016, 184, 374-386. [CrossRef]

67. Drăguț, L.; Tiede, D.; Levick, S.R. Esp: A tool to estimate scale parameter for multiresolution image segmentation of remotely sensed data. Int. J. Geogr. Inf. Sci. 2010, 24, 859-871. [CrossRef]

68. Dragut, L.; Csillik, O.; Eisank, C.; Tiede, D. Automated parameterisation for multi-scale image segmentation on multiple layers. ISPRS J. Photogramm. Remote Sens. 2014, 88, 119-127. [CrossRef]

69. National Bureau of Statistics of China. National Data. Available online: http:/ / data.stats.gov.cn/english/ easyquery.htm?cn=E0103 (accessed on 11 March 2018).

70. Pedregosa, F.; Varoquaux, G.; Gramfort, A.; Michel, V.; Thirion, B.; Grisel, O.; Blondel, M.; Prettenhofer, P.; Weiss, R.; Dubourg, V. Scikit-learn: Machine learning in python. J. Mach. Learn. Res. 2011, 12, 2825-2830.

71. Ghulam, A.; Li, Z.-L.; Qin, Q.; Yimit, H.; Wang, J. Estimating crop water stress with ETM+ NIR and SWIR data. Agric. For. Meteorol. 2008, 148, 1679-1695. [CrossRef]

72. You, J.; Li, X.; Low, M.; Lobell, D.; Ermon, S. Deep gaussian process for crop yield prediction based on remote sensing data. In Proceedings of the Thirty-First AAAI Conference on Artificial Intelligence, AAAI, San Francisco, CA, USA, 4-9 February 2017; pp. 4559-4566.

73. ESA. First Sentinel-2B Images Delivered by Laser. Available online: https://www.esa.int/Our_Activities / Observing_the_Earth/Copernicus/Sentinel-2/First_Sentinel-2B_images_delivered_by_laser (accessed on 11 December 2018).

74. Massey, R.; Sankey, T.T.; Yadav, K.; Congalton, R.G.; Tilton, J.C. Integrating cloud-based workflows in continental-scale cropland extent classification. Remote Sens. Environ. 2018, 219, 162-179. [CrossRef]

75. Sundermeyer, M.; Schlüter, R.; Ney, H. Lstm neural networks for language modeling. In Proceedings of the Thirteenth Annual Conference of the International Speech Communication Association, Portland, OR, USA, 9-13 September 2012.

76. RuBwurm, M.; Körner, M. Temporal vegetation modelling using long short-term memory networks for crop identification from medium-resolution multi-spectral satellite images. In Proceedings of the CVPR Workshops, Honolulu, HI, USA, 21-26 July 2017; pp. 1496-1504.

(C) 2019 by the authors. Licensee MDPI, Basel, Switzerland. This article is an open access article distributed under the terms and conditions of the Creative Commons Attribution (CC BY) license (http://creativecommons.org/licenses/by/4.0/). 